\title{
THE BEARING OF THE DRAYSON THEORY ON THE PROBLEMS PRESENTED BY STRIATED NEOLITHIC FLINTS.
}

By the President (W. Allen STURGe, M.V.O., M.D., F.R.C.P.)

(Read at Norwich, December gth, Igr2.)

\section{Ladies and GentLemen,}

I propose in this address to give you some account of my work during the past two or three years bearing on the difficult problems of prehistoric chronology. You may remember that to the first number of the "Proceedings" I contributed a paper on this subject. Since that time I have been continuously occupied with it, and I believe I have made some advance, both as regards facts and as regards theory.

It will be within the recollection of you all, that in the paper alluded to, the fact round which everything else pivoted was the striation of certain classes of neolithic flints. The cardinal fact to which I would call attention to-day is the occurrence of other classes of presumably neolithic flints which show the striking peculiarity of being patinated on one side only, or if both sides are patinated, one side is very much more so than the other. My attention was drawn to the peculiarity in this way: For some time past large numbers of flint implements and flakes have been brought to me by the labourers on an estate a few miles from Icklingham. Some of them were picked up when the men were engaged in their usual work on the land. But a considerable number were found in the process of digging over a plot of ground a few score acres in extent with a view to making a new plantation. This ground formed part of the uncultivated sandy heathland which is so striking a feature of the neighbourhood. It is believed that the ground has never been ploughed nor even dug up before, and as the digging was carried to a depth of two feet, or thereabouts, these flint implements were thrown up with the upturned soil in which they had remained undisturbed from time immemorial. It was amongst these that I first noticed the pieces with one-sided patinations. The patina on the one side is blueish-white, the white predominating as a rule over the blue; and there is a curious mottling of the surface which is very characteristic. The other side presents the natural colour of the flint, black or brown as the case may be, with no sign of patina. Many of these implements are scrapers, and it is sometimes the worked side and sometimes the bulbar side that is patinated. I mention this to show that the difference of patination is not due to the implement having been made at a later date out of a flake struck off by an earlier man which had become patinated. Occasionally such a two-period implement is met with, but such implements are quite different in appearance from thuse with which I am dealing, and it is obvious that where it is the worked 
side of a scraper that is patinated and the flake side unpatinated, such a solution of the problem is impossible. An examination of a considerable number of such flints will make it quite evident that we really are dealing with one-sided patinations of a single period. (Plate LIX. Figs. 1-8.)

Now, mark! None of these pieces is striated, none of them is iron-moulded, very few of them are lustred. Those who are not familiar with my work on striated flints will perhaps not see the full force of this; but those who have read my paper on "Chronology," or can refer to it, will know the importance I attributed to the association of these three factors in dealing with neolithic flints in this part of the country. The presence, therefore, of one-sided patinations and the absence throughout this series of these other characteristics, points to a difference of period for this class when compared with the various classes showing the peculiarities indicated.

The series just described is, however, not the only one showing difference of patination on the two sides. In it the difference is at its greatest, there being marked patination on one side and none whatever on the other. There is another sharply-defined series in which one side is patinated a very pure white with no sign of blue or other colour feature, whilst the other side is of the same blueish-white as was seen on the patinated side of the series first described. When a large number of these are seen together, the effect is very striking - almost as much so as in the case of those with one side quite unpatinated. As was the case with these, the series in question shows neither scratching, ironmoulding, nor lustre. Some very fine implements belong to this category. What is their period? Is it the same as that of the first series? I am not sure that these questions can be answered at present; at any rate, I will postpone discussion of them till a later part of my paper, when I shall offer suggestions as to the causation of these strange phenomena. (Plate LX. Figs. 1-9.)

The two series here described by no means exhaust the question of different patination on the two sides of neolithic flints. Although neither of these series was associated with conditions producing striation, iron-moulding, or lustre, yet a state of things. somewhat similar to that which produced these differences of patination seems to have occurred during the periods when flints were subjected to the other very special conditions. The differences in patination on the two sides are in their case less marked in degree than were described under the first two headings, but a certain number of such flints do show a difference quite sufficiently marked to attract attention. The patinas are similar to those found in the great bulk of flints of this kind, blue, or blue somewhat mottled with white, and they are scratched, lustred, and iron-moulded, some more and some less. I had noticed these pieces before my attention was specially drawn to the question; but it was not until the flints of my first described series came in in considerable numbers that I began to give thought to the sub- 
ject and to recognise that this peculiarity is a remarkable one, and that an effort should be made to find out what it really means.

This feature of one-sided patination is not confined to neoliths. In former papers I laid stress on the fact that it is one of the characteristics of certain flints from the Warren Hill gravels, chiefly amongst the well-known ovates from that deposit. It is not present in by any means all of these ovates, the proportion being roughly about 1 in 4 . As with the two series of neoliths I first described, the patinated side, or the side showing most patination, is white or whitish. The other side may be black, or whatever the original colour of the flint may have been; or it may have acquired some wholly different patina_for example, the well-known "toad-belly" patina of Warren Hill. On the other hand, it is rare to find the "toad-belly" as the predominant patina.

One-sided patination is also present in the case of some of the late Palæolithic (Cave) implements and flakes from the Wangford "floor." Here, again, there are two principal series; one in which there is a patinated side, the patina being pearly blueish-white, the other side being unpatinated; and another series where one side is pure lustrous white, or white with a slight tinge of orange, the other side being patinated of the same pearly blueish-white as seen on the patinated. side of the first. mentioned series.

What is the meaning of this strongly-marked characteristic which crops up in certain groups of implements and flakes belonging to many different periods? I described the peculiarity in my paper on "Patination" in the second number of our "Proceedings." I there attributed it to the action of strong sunheat, and perhaps light. Since writing that paper I have seen no reason for altering the view $I$ then took of the matter. On the contrary, though I have considerably added in the meantime to the various series of on -sided patinations, I have been more and more impressed with the idea that this is the correct interpretation of the pheno senon. It is quite certain that nothing of the kiind is going ' $n$ to-day, at any rate in flint of the fine quality of which these implements and flakes are made. It is equally certain that it was only at recurrent intervals of time in the past that the conditions arose that gave rise to it; for although I have many hundreds of pieces of various periods showing one-sided patination, or patination of markedly different character on the two sides, yet the proportion they bear to the many thousands of implements and flakes which show nothing of the kind is a small one. As I pointed out in my paper on "Patination," the phenomenon is present in a large number of Egyptian implements of the "drift" periods, and in their case it has always been assumed-and no doubt rightly assumed - that it is due to the action of the Egyptian sun.* The

* It is also seen in a very marked degree in the large series of implements brought by Mr. H. W. Seton-Karr from the neighbourhood of the flint mines in the Wady Shekh, specimens of whish are in most museums. 
same explanation is applicable to the case of our flints, and I feel justified in predicating in their case the action of sun-heat and light of a much stronger character than obtains to-day.

In thus describing the various series of humanly-worked flints with one-sided patination, or with patination varying in quality or in degree on the two sides, I wish it to be understood that I attach very great importance to these characteristics. I go so far as to assert that they are second only in the value of the evidence they afford to the striation of flints. The reasons for this assertion I hope to make clear when I pass to the theoretical side of the subject.*

In regard to the subject of flint-striation, I have nothing new in the way of facts that I need quote on the present occasion. What I wrote about it in my paper on "Chronology" still holds. Large numbers of striated flints have been added to my collec. tion, chiefly from my own neighbourhood, but to a certain extent also from outside - the more distant parts of Suffolk and Norfolk, from Hampshire, Dorsetshire, and elsewhere. Attention has been called hy Mr. Thomas George, of Northampton, to the occurrence of striated Neolithic flints in certain areas near that town. I understand that they are found in Belgium, and I have some in my own collection from Campigny, in the Department of Seine Inférieure. I make no claim to final settlement of the questions concerning the sub-divisions of periods of striation; I think it not improbable, for instance, that the period I called No. 5 in my paper on "Chronology," the series of flints with white or blueish-white patination, and striation exclusively or almost exclusively by fine quartz sand, may have to be shifted from the position I there gave it. But these are details which have no immediate effect on the picture which I drew of the striating conditions.

There is one further very important fact to be noted as having come to my knowledge since my paper on "Chronology" was written. This is the assertion hy the Swedish geologist, the Baron de Geer, that there was a glaciation in Sweden as lately as 15,000 years ago. I believe the proofs of this statement are not accepted by all geologists in Sweden; but I understand that many of them consider that the Baron de Geer has made out his case; and I know that some distinguished English glacialists who have gone fully into the question are of the same opinion. Professor Sollas has even incorporated it into his book on "Ancient Hunters," and has founded a syslem of chronology of the Stone Age on the de Geer position. He identifies this very recent glaciation with Penck's Würmian glaciation, and, on the strength of this attribution, gives us a chronology to which I venture to give the name of a latter-day Ussherism. I need scarcely say that I differ in toto from my friend Professor Sollas.

* Since this Address was delivered, a remarkable discovery has been made at Icklingham, bearing on the subject of one-sided patination. This is dealt with in a postscript. 
But I am perfectly ready to accept the statement of Baron de Geer. I am in no way qualified to express an opinion upon the validity of his evidence. If those, however, who are qualified to do so express their belief in its valicity, I am in a position to say that the assertion of the existence of glaciation in Sweden 15,000 years ago fits in with my own evidence perfectly well.

This will come as a fresh statement to any of you who remember the point that I reached in my paper on "Chronology," already referred to. You may recall that in that paper I had only the Croll theory to fall back upon in explanation of the recurrent glaciations in Neolithic times. According to this theory, which bases the occurrence of glacial periods in what are now temperate latitudes upon the increase beyond a certain limit of the ellipticity of the earth's orbit, the most recent time when an ellipticity of this order obtained ended about 80,000 years ago. Accepting Croll's theory as the only one then before me, I had very tentatively to postulate this great lapse of time since the last striating conditions were present in this part of the world, and therefore to put the period of my No. 6 scratches as far back as that remote time. I was never really satisfied that this could be true. The thousands of implements and flakes in my collection which belong to this latest class of striated flints, are in other respects so freshlooking and many of them are of such high quality of work that it is difficult to believe they are so old as $I$ then stated. And another point has struck me. Although there are very considerable numbers of implements obviously belonging to the end of the Neolithic or, perhaps, to the early bronze period, which are quite unpatinated, unlustred, unscratched, and without iron-stains, yet the aggregate number of them is very definitely below that of the flints included in my No. 6 class of striation, and very far inferior to that of flints of all classes of striation. Take scrapers, for instance. I have about 70 cabinet drawers full of scrapers from this district. At the outside, the number of scrapers belonging to the post-striation period is not more than enough to fill five of these drawers-a proportion of not more than seven or eight per cent. If the final glaciation took place so long ago as 80,000 years, there must have been a period of not less than from 60,000 to 70,000 years during which Neolithic man of the final, post-glacial stage would have possessed the land undisturbed. This would probably be equal to all the interglacial periods of Neolithic time put together. It would certainly hold a very much higher relationship to the whole time of the Neolithic period than is represented by the seven or eight per cent. just named. A fortiori it would have an enormously higher percentage as compared with the single interglaciation that preceded the final appearance of the ice, and which is represented by scrapers of the No. 6 scratched series. Yet these latter are more numerous than the late unpatinated, unscratched pieces. 
I was therefore driven to the conclusion that whatever truth there might be in the Croll theory it was not the whole truth, and that, sooner or later, it would be supplemented by some other explanation.

I had not long to wait. But before going on to this story, which will occupy the rest of my paper, I propose to give a short summary of the various conditions as illustrated in this neighbourhood, and which have to be brought into line with one another and with any theories that may be invoked for their explanation. These are :-

1. The occurrence during the Neolithic period of glaciations on a minor scale which have left their marks on the fine chalcedonic flint of the neighbourhood. I make out seven of these recurrences. I lay no claim to exact accuracy, but in so far as I am wrong in my number it is practically certain that I err in understating it. But whether the correct number be two or ten it makes but little difference in the principle of the assertion. The exact number is merely of importance in arriving at the length of time that the whole Neolithic period lasted.

The series of glaciations thus predicated ended with one that in these parts was of very small dimensions, my No. 6, which may, without much doubt, be co-ordinated with the Swedish glaciation of 15,000 years ago. Being so much further north, the glaciation in Sweden was on a larger scale, though I take it that even there it was in no sense comparable with the gigantic glaciations of "The Great Ice Age."

In passing backwards in time the Neolithic glaciations increase in volume until a point is reached, named by me the No. 1 glaciation, when the scale was relatively large, and from that point backwards a lessening takes place until all evidence of glaciation disappears. The nre-No. 1 glaciation, which is very largely represented here, is that associated with my "Old-White" civilization. This glaciation was also relatively severe. Other pre-No. 1 glaciations are difficult to localize ; there were probably others, but these may, for the present, be left out of account. The important point is that the working $u p$ to a maximum seems to have involved much less time, and consequently a smaller number of recurrences of glaciating conditions than the working dozen from the maximum to the present day.

2. Behind this great series of Neolithic glaciations there are the quite evident signs of a stage of Neolithic culture of a high order, and probably lasting for a very long time. In its turn this pre-glacial Neolithic period would seem to be divisible into subperiods. 'I he outstanding feature of the implements of this period $i_{s}$ the presence of a thick white patina, porcelainous or nonporcelainous. White patina of a somewhat different kind, tending to merge into blue-white, and so into light-blue, occurs very largely on the implements of my "Old-White" period. After this period white patina would seem to disappear. In my paper on "Chronology," I placed the series of white or blue-white pieces 
with sand scratching, which I have already referred to as my No. 5 's, late in the chronology; but as already remarked, I think it is not improbable that I was wrong in this and that they ought, on the contrary, to be placed very early in that chronology. Leaving this particular series on one side, the statement is, $I$ believe, correct that white patination in this neighbourhood ended with the "old whites" which, so far as at present known, formed one of the earliest of the scratched series. Behind the "old whites" white patination becomes the rule, and the great series of the older neoliths is distinguished by the presence of this patina. This older series seems to be again divisible into two main parts, one of which shows a degree of iron-moulding greater than that of any other series; whereas the other is distinguished by a complete or almost complete absence of iron-moulding. In the first category, that with a high degree of iron-moulding, is included a very considerable number of flint axes and other implements with more or less extensively polished surfaces. I have between sixty and seventy axes of this kind from this neighbourhood, and I have a considerable number of axes showing precisely similar characteristics from other parts of England and from France. The second category also contains polished flint axes, etc.; and the contrast between the two series is very great. The subject is one of great interest and importance. All I need do here is to emphasize the existence of a prolonged Neolithic period, showing a high degree of culture, behind the whole of the periods of striated flints; and to point out that one great characteristic of pieces belonging to this early Neolithic time is the presence of white patination in sharp contradistinction to the pieces belonging to most of the scratched series, and to those which date from after the close of the scratched periods. The great predominance of white patination at that time, and its virtual absence at all later times, is a very important factor in dealing with our subject. I shall doubtless be asked: "What about the presence or the absence of iron-moulding in the two main divisions of this early Neolithic period? What does that mean?" I can only confess my ignorance. It is a great puzzle; and if this puzzle could be cleared up I feel sure that we should have another very important factor for reading the past history of the globe. Iron-moulding was present in "old white" times, and throughout the earlier "scratched" periods; but it practically disappeared after my No. 3 period. In no case, however, is it comparable with that seen on these early polished implements which show no signs of having been subjected to glacial conditions.

3. When we get behind the Neolithic period altogether, and touch on what would seem to be the end of the later Palæolithic "Cave" periods, as represented by the older series in the "floor" at London Bottom, we still find white patination. All the pieces of this older series at London Bottom are dead white, in sharp contrast to those of the later series in the same deposit. And not only so but there are many series composed of large implements 
and flakes scattered over a wide area of country, from Norfolk to Sussex, which show this same white patination. The series from Grime's Graves and from Cissbury are the best known, but many other similar ones occur. The whiteness of these pieces is exactly comparable with that of the older London Bottom series. Yet it is practically certain that none of those hitherto examined belong to the same period as the older London Bottom flints. These are entirely composed of very definite "Cave" types; the Cissbury and Grime's Graves pieces on the other hand are largely composed of types which hitherto have been looked upon as Neolithic, long chipped axes being a predominant feature. Mr. Reginald Smith has recently written a very able paper to show that the class of work represented at Grime's Graves and Cissbury dates from Aurignacian times. This is not the place to make any general criticism of his thesis, but I may go so far as to say that the presence of the white patina universally found on flints of the period, whatever it may be, wherever they are found, points to their belonging to a great period of white patination. We have seen that our evidence shows that our latest "Cave" things and our earliest Neolithic come within this category. Hitherto the Cissbury - Grime's Graves pieces have been supposed to belong to some very early Neolithic period. Judging by their patina it would seem to be a question whether, if they are to be included in the later Palæolithic "Cave" period, they should not be put at the very end of it rather than so far back as the Aurignacian. There is rothing in this part of the world to show that there was any period associated with white patination in Aurignacian times; whereas we have very clear evidence that there was a great period associated with white patination at the very end of the "Cave" periods and at the beginning of the Neolithic period. Is it not probable that all these finds of the Cissbury-Grime's Graves order belong to this time?

I have laid great stress upon this occurrence of white patination through a certain course of ages and its absence at other times, because I believe it to be one of the cardinal factors in the case I am about to unfold.

4. From such observations as can be made in this neighbourhood it would appear that there was no occurrence of glacial conditions during the later Palæolithic period, that represented by the Magdalenian, the Solutrean, and the Aurignacian ages. Behind the Aurignacian, and separating it from the Mousterian, was a glaciation on a great scale which I have correlated with the Würmian glaciation of Penck. This is splendidly represented in this district; but after it had passed away there is no evidence of glaciation until on a minor scale the long series of Neolithic glaciations set in. How long a period of time elapsed between the finish of the Würmian and the beginning of the Neolithic glaciations there is nothing that I know of to indicate. It is prictically certain that the period must have been a very great one, since four civilizations at the very least came into it, viz.: the 
three great "Cave" periods just mentioned, and more than a commencement of the Neolithic. Not only has the time required for each of these great civilizations, with their many subdivisions already known, to be accounted for, but everything points to the probability that between each of them, between the sub-divisions even, there were periods of greater or less length during which Man was not present in Western Europe. The evidence of this is seen in all caves that contain a succession of human remains belonging to a succession of different periods, "sterile" deposits being intercalated between the "fertile" deposits, and these sterile deposits are often quite as thick as the fertile.* It is difficult to avoid the conclusion that we are dealing with periods of great length, but it is not easy to go beyond this general statement. Two considerations may come in to help us. The first is that of analogy, the comparison of the length of the immediately preceding and immediately following periods. We already knew that the Mousterian period lasted through two widely different climatic phases, sub-arctic and sub-tropic, The researches in the Grotte du Prince at Mentone proved this. And now we have a discovery by $\mathbf{M}$. Commont of a Mousterian deposit in the valley of the Seine, associated with the remains of subtropical animals, in contradistinction to the great bulk of such deposits which show sub-arctic relationships. Under any explanation of gross climatic change such as that indicated here, time on a large scale must be preaicated; and in all the long time thus indicated for the Mousterian period there was practically no advance in human culture. Take again the Neolithic period. Here I perhaps stand alone; but whatever may ultimately emerge from my researches in this direction, one thing is quite certain, viz.: that time will have to be drawn upon on a vast scale.

A second consideration is the extension over wide areas' of identical cultures. Every one of the "Cave" periods is represented over practically the whole of Europe, except perhaps the most northerly portion-Scandinavia, and the North of Russia. And they are represented outside Europe; certainly in North Africa, in Syria, and probably much further afield. It is astonishing with what fidelity they are thus represented. Minute details in the make of implements occur in places separated from one another by hundreds, perhaps thousands, of miles. This phenomenon was repeated over and over again, and it is impossible to believe that so wide a spread of phases of culture, time after time, was effected in short periods. The combined effect of the evidence is to point to great lapses of time for the inclusion of all these various stages of development. Yet during all this period there seems to have been no glaciation; in marked contrast to what took place before and after. There may have been some lesser climatic changes, for certain pieces which would seem to belong to the Solutrean period have been found in brick-earths.

* "Fertile" is used to denote strata with human remains. "Sterile" indicates strata with no trace of human remains. 
Moreover, a series of "Cave" implements that probably belong to some pre-Solutrean period have been found in a brick-earth at Ipswich by Mr. Moir. There is, however, nothing to show that any of these had been subjected to glacial conditions.

5. It is a remarkable thing that the long period of relative quiescence occupied by the three great divisions of the later Palæolithic (Cave) Age, and by the earlier Neolithic period, was immediately preceded by the great Würmian glaciation, which apparently brought the Mousterian period to a close. And the Würmian glaciation was only the last of a series of great glaciations. Four of these have been detected and traced by Professor Penck. There were almost certainly others, as the whole history of the Palæolithic gravels is involved. No one who has not worked at a large number of these gravels and at their Palæolithic contents can appreciate how complex is the story of gravel formations. It is, however, enough for my present purpose to postulate these four great glaciations ending with the Würmian, to be followed by the long period of quiescence mentioned in the last paragraph.

6. Finally we have to take into account the occurrence at different periods, from those of the drift gravels, through the Cave periods, and in certain of the sub-divisions of the Neolithic period, of implements patinated on one side only, or very much more so on one side than on the other. This very marked peculiarity points almost certainly to sun-heat and light as the patinating causè ; and as there is no reason to believe that anything of the kind is taking place to-day, it leads us to postulate a much greater degree of sun-heat and light in these latitudes in times past than now obtains. The evidence of the flints shows that this patinating influence was by no means always present, but that it occurred at intervals - the periods between these intervals being associated with patinating conditions that acted equally on all parts of the flint.

To sum up; we have to consider-

1. A series of minor glaciations in the Neolithic period.

2. A more or less prolonged phase of Neolithic culture behind the first of these glaciations.

3. Absence of glaciation during the Magdalenian, Solutrean, and Aurignacian phases of culture.

4. Behind the Aurignacian, and between it and the Mousterian period, the great Würmian glaciation.

5. Behind the Mousterian period a series of great glaciations tabulated by Professor Penck.

8. The presence at certain times during all the periods of the Stone Age of conditions that led to the one-sided patination of flints.

I now pass to the interpretation of the writing on the flints. In my former paper I had nothing but the Crollian hypothesis to help me. I have already said that I felt that something more was necessary, and I had not long to wait before I received what 
I believe to be a most important addition to my armoury in attacking these most difficult problems. One result of the publication of my paper on "Chronology" in the first number of our "Proceedings" was to bring me a letter from Major Marriott, D.S.O., the Governor at that time of Chelmsford Gaol, now of that at Lewes, in which he asked me whether I had thought of the Drayson theory as an aid to the interpretation of the phenomena described in the paper. I had never heard of Drayson or his theory, and was perhaps inclined, as we too often are in these matters, to treat the question in an offhand manner. But Major Marriott took pains with me, and I began to look seriously into the question, with the result that it was not very long betore I saw that this was just the thing I was looking for.

I expect that most of my readers will be in the same state of ignorance regarding Drayson and his work that I was before hearing from Major Marriott, and I propose to give, as shortly as is consistent with clearness, an outline of the conclusions he came to. I am quite aware that I am treading on even more tender ground than when I referred to Croll in my former paper. I have no means of testing Drayson's work from his own side-that of astronomy and mathematics. I can but take his conclusions and see how they fit my facts. If they fit throughout, well and good; if they fit partially, still well and good. If I had found that they had no application to my own work I should not be bringing the subject before you. My doing so is proof that I have derived help from him-much-needed help-and if I can make the exposition of the Drayson theory in its relation to my story as interesting to you as the work has been to me, I shall feel that no apology is necessary for taking you into a rather abstruse field of study.

One word before I begin. I am not here to dethrone Croll; I believe that Croll is as necessary as Drayson for the explanation of the extraordinary climatic changes indicated in the above summing up of the conditions to be accounted for. Croll and Drayson, taken together, give us a very powerful instrument for interpretation. It is not likely that with them we have reached the last word on the subject, but it is all that, so far as I know, we have at present. The two combined can, I believe, carry us many steps further than either of them can take us when used alone. Probably secondary factors will come in, such for instance as the deflection of the Gulf Stream, but I do not propose to go into any of these secondary questions, for our knowledge is not yet sufficient to deal with them. It is the great primary causes that must first be arrived at.

And now for my story. Major-General Drayson, R.A., after his service in the Royal Artillery was for two years an assistant at Greenwich Observatory, and for many years Professor at the Royal Military Academy at Woolwich, where the young officers for the scientific branches of the Army are trained. In the course of his work he was profoundly struck with the fact that it is not possible to calculate the 
exact positions of the stars for the purposes of the Nautical Almanac, but that they have to be determined by frequent observation. He was, moreover, equally struck by the fact that it seems impossible by calculation to get the true astronomical time. If all the motions of the earth were understood, he argued, calculation should be all that would be required to obtain exactitude in both these respects. He therefore set himself the task of endeavouring to ascertain what was wrong in our knowledge of the earth movements, and whether by discovering the error and basing our calculations on the new data, it would not be possible to obtain formulæ which should work out the problems with such exactitude that all these repeated observations would become, and would be recognised as, unnecessary. To this task he applied himself for many years. The result was that he claimed to prove that the error that gave rise to the trouble lay in the fact that a wrong centre was being taken for the movement of precession, the movement by which, as is well known, the poles of the earth's axis revolve in the heavens in a period of a certain number of thousands of years. It is stated in all works on astronomy that this movement takes place round the pole of the ecliptic as a centre, that is to say, round the line drawn at right angles to the plane of the earth's orbit, and passing through the earth's centre. Drayson announced that he had discovered that this was not the centre of revolution of precession, hut, on the other hand, that the centre really was a point removed 6 degrees from the pole of the ecliptic, and on this basis he prepared a series of formulæ which gave exact positions for the stars, not only for the current year, but for any year past or future. For instance, if the observed position of a given star in 1887 were taken he could calculate its position for (say) 1837 or 1787 , with the result that his calculated positions corresponded within the fraction of a second with the observed positions for those years, as stated in their respective Nautical Almanacks. I am, of course, totally unable to check this side of his argument, but to the lay mind the statement appears to be a strong one to make, and one that ought to be perfectly capable of examination by the expert, for corroboration or the reverse.*

What is the cause of this deflection of the centre of precession movement from the pole of the ecliptic? It seems to be due to the fact that the earth acts as a gyroscope. Let a gyroscope be taken so constructed as to have three movements round the centre of the system. Let the body of the gyroscope be tilted over so that its axis holds the same position towards the plane of the floor of the room that the axis of the earth bolds to the plane of its orbit-the ecliptic. Then start the gyroscope spinning on its axis. This is its primary movement, and corresponds to the primary (daily) rotation of the earth. With a properly-

* Drayson's calculations were carefully examined and worked through by Admiral Sir Algernon de Horsey, K.C.B. He confirmed their accuracy, and published his results in "Draysonia." (Longman's, 1911). 
applied force the poles of the axis of the gyroscope can be made to rotate in circles, having for their centre the imaginary line drawn from the plane of the floor of the room through the centre of the gyroscope. This is called the precession movement of the gyroscope, and is its secondary rotation. This corresponds to the precession movement of the earth, where the force applied is the attraction of the sun and moon on the protuberance of the earth at the equator. In order that the secondary movement of the gyroscope shall take place with the above-mentioned line as the centre of the circles described by the poles, the gyroscope must be made with mathematical accuracy, so that the centre of gravity of the gyroscope corresponds exactly with the centre of the gyroscope. The least departure from this, as by the placing of a small piece of wax or of a pin on one side of the gyroscope, will immediately deflect the centre of rotation of the poles of the gyroscope (precession movement) from the line above-mentioned, and the deflection will be out of all apparent proportion to the alteration of the centre of gravity produced by this small onesided addition to the weight of the instrument.

If we apply these principles to the earth, what do we find? Very little is known of the interior of the earth, and I suppose that it is at present impossible to say from that point of view where the centre of gravity would be if the earth were in shape a uniform spheroid. But we do know quite definitely that it is not a uniform spheroid. The amount of land surface in the northern hemisphere is enormously greater than that in the southern. I have made no attempt to calculate the difference accurately, but it works out roughly at something between twenty and twenty-five millions of square miles. Assuming that the average height of this great extent of country amounts to a fifth of a mile-about 1,000 feet, we have four to five millions of cubic miles in the northern hemisphere which are not represented in the southern. But there is a much greater difference in the two hemispheres than this alone would show. These twenty to twentyfive millions of square miles of extra land surface in the northern hemisphere rest upon a solid substance at least equally heavy with themselves, which in the southern hemisphere is represented to a certain depth by water. This depth may be taken as an average of three miles-the average depth of the great oceans. Therefore we have in the northern hemisphere seventy-five millions of cubic miles, with a specific gravity of probably not less than three, which is weighted against a similar number of cubic miles in the southern hemisphere with a specific gravity of (roughly) one. These seventy-five millions of cubic miles in the northern hemisphere therefore weigh three times (at least) as much as the corresponding cubic miles in the southern hemisphere, and this great extra weight has to be added to that already postulated for the extra land above sea level in the northern hemisphere. It is scarcely necessary to try to express this in tons, but it sums up into many hundreds of thousands of 
billions (millions of millions) of tons. I shall doubtless be met by the assertion that this counts for nothing, as the whole question is one of relative weight-the relation between this great absolute weight and the weight of the whole earth. Of course, this is an important matter, but here it is that the gyroscopic features come in. Though the ratio may be a small one-somewhere, I believe, in the neighbourhood of 1 to 4,000 or 5,000 , yet it comes well within the bounds of ratio between the gyroscope and the tiny dab of wax or the pin attached to one of its surfaces which are sufficient to deflect appreciably its centre of secondary rotation. And another point should, I believe, be noted here, viz: the ratio between the rapidity of primary rotation, and that of secondary rotation. This in a gyroscope would not exceed a few thousands to one, whereas in the earth we are dealing with a ratio of many millions to one. I believe I am right in saying that astronomers bave never been able to arrive at a settled period for precession, and that the figure generally given, about 25,000 years, is a mere average taken from several rather widely-varying results. Drayson puts it at about 31,700 years. In any case, when these figures come to be multiplied by 365-the number of primary rotations in each year, we arrive at the result roughly given above.

Now if the secondary rotation (the precession movement) of the earth is to take place round the pole of the ecliptic as a centre, the centre of gravity must strictly correspond with the centre of the earth, in other words the gyroscope must be made with mathematical accuracy. But it is obviously impossible that this can be the case, therefore it seems to me to be impossible to controvert the assertion that the one centre round which the earth can not rotate in its secondary movement is the pole of the ecliptic. Therefore the centre of secondary rotation must be removed by a certain distance from the pole of the ecliptic. Drayson worked at this problem for many years from a purely astronomical standpoint, and he came to the conclusion that the centre of secondary rotation (precession) was removed, as above said, six degrees from the pole of the ecliptic.

Let us consider the effect of this change in our views of the position of secondary rotation. They are very startling, involving the most startling changes in our ideas that have taken place since the days of Copernicus. I suppose that to most of us it is almost unthinkable that in this twentieth century there remain undiscovered facts about our earth that may be placed on a level with the fact of its'daily rotation. You may well believe that I, with a mere smattering of astronomy and mathematics, should never set myself up to champion vast changes of ideas in these great subjects from the astronomical or mathematical standpoint. This would be presumptuous in the last degree. But, as most of you are aware. I do champion changes in our ideas in prehistory, and therefore in geology, which in their way are about as far-reaching as Drayson's announcement of the new centre of 
rotation. I claim a perfect right to do this. I have a vast amount of evidence which no one else has; I have studied it for many years. I know better than anyone that I am far from having got to the bottom of it, but $I$ do know that $I$ have arrived at certain conclusions that I deem irrefragable, and these conclusions on so seemingly different a subject, fit in with Drayson's astronomical conclusions as a glove fits on the hand. Is it any wonder that I acclaim Drayson's work, and that I call for fresh investigation of it from the astronomisal side?

What then are these startling results? Let me state briefly the first and almost overpowering one. It is this: Fifteen thousand years ago the Arctic Circle was at Durham, and the Tropic of Cancer was at Gibraltar.

It is enough to take away your breath, as it did mine when first I began to look seriously into the matter. How does it come about from the premises? How is it that the mere shifting of the centre of secondary rotation (precession) should have such results? A very little reflection will show the cause and effect. If the precession movement takes place round the pole of the ecliptic-in other words round the line drawn at right angles to the plane of the earth's orbit through the earth's centre, as is always assumed by astronomers, then the obliquity of the earth's axis to the pole of the ecliptic will always remain the same at all periods of the precession movement. This is to-day about $23^{\circ} 27^{\prime}$ and this it would remain always, subject to slight annual variations known as nutation, which, however, in the present context may be left out of account. If, on the other hand, the centre of the precession movement does not coincide with the pole of the ecliptic, then it is inevitable that the distance of the pole of the earth from the pole of the ecliptic, in other words the obliquity of the earth's axis, must vary at different stages of the precession movement. To take the extremes, at one time the distance between the pole of the ecliptic and the centre of secondary rotation (precession) will be added to the distarce from the centre of secondary rotation to the pole of the earth, and at another time it will be subtracted from it. Taking the distance of the centre of secondary rotation from the pole of the earth at the value assigned to it on astronomical grounds by Drayson as $29^{\circ} 25^{\prime}$, and the distance of the centre of secondary rotation from the pole of the ecliptic at $6^{\circ}$, then the distance of the pole of the ecliptic from the pole of the earth will at one time be $29^{\circ} 25^{\prime}-6^{\circ}$, viz., $23^{\circ} 25^{\prime}$, and at another time it will be $29^{\circ} 25^{\prime}+6^{\circ}$, viz.: $35^{\circ} 25^{\prime}$. But these figures represent the obliquity of the earth's axis ; therefore the obliquity of the earth's axis is sometimes as low as $23^{\circ} 25^{\prime}$, very slightly less than the present obliquity; whilst at other times it is as high as $35^{\circ} 25^{1}$. It is the degree of obliquity that determines the positions of the Arctic and Antarctic Circles and of the Tropics; the Arctic and Antarctic Circles being at the same distance from the poles, and the Tropics at the same distance from the Equator as the figure representing 
the obliquity. At present the obliquity is about $23^{\circ} 27^{\prime}$; therefore the Arctic and Antarctic Circles are situated $23^{\circ} 27^{\prime}$ from their respective poles ; in other words, in latitude (north or south as the case may be) of $66^{\circ} 33^{\prime}$; whilst the Tropics are situated $23^{\circ} 27^{\prime}$ from the Equator; in other words, in that latitude (north or south as the case may be).

If, however; as shown above, the obliquity rises to $35^{\circ} 25^{\prime}$, then the Arctic and Antarctic Circles will be at that distance from their respective poles, viz.: in latitude $54^{\circ} 35^{1}$; whilst the Tropics will be the same distance from the Equator, viz.: in latitude $35^{\circ} 25^{\prime}$ (north or south as the case may be). Put into concrete terms, this means that the Arctic Circle will come down to Durham, and the Tropic of Cancer will come up close to Gibraltar.

As I have indicated above, we are just approaching the minimum of obliquity. This is $23^{\circ} 25^{1}$, the present obliquity being $23^{\circ} 27^{\prime}$. We shall reach the point of minimum obliquity in about 320 years. According to Drayson, the period of precession movement is 31,700 , and therefore the earth was at its period of maximum obliquity between fifteen and sixteen thousand years ago. At that time, therefore, the Arctic Circle came down to Durham and the Tropic of Cancer came up to Gibraltar.

I fear I shall have wearied you with this somewhat technical exposition; yet it is necessary to get some grasp of it if you are to understand the application of it to my own particular subject. Let me once more repeat that I am in no way responsible for these figures. The short exposition I have given follows quite simply and inevitably from Drayson's postulate that the centre of second rotation (the movement of precession) is situated, not on the pole of the ecliptic, but at a point $6^{\circ}$ removed from that pole. He arrived at this conclusion after a long research, and he claimed to have proved it by the accuracy with which he could caleulate the position of any of the stars for any year, a proceeding which is known to be impossible if the pole of the ecliptic be taken as a centre.

It lies outside my province to defend Drayson from his critics, my object being to apply his results to the explanation of the extraordinary phenomena of the striation of fine flints, both neolithic and palæolithic. But there is one question that my friends almost always ask me, to which I may here refer, viz.: "If this assertion of Drayson's be true, why is it that it cannot be at once put to the proof by astronomers?" The answer to this question would seem to be that the obliquity of the earth's axis at the present day holds a relationship so close to the minimum obliquity, that for observational purposes it makes very little difference whether the centre of secondary rotation be assumed to be on the pole of the ecliptic or at $6^{\circ}$ from that pole. This is a simple geometrical statement which anyone can easily prove for himself. Eight thousand years ago it would have been very different, and a very few years' observations would then have sufficed 
to clear the matter up. Still there is even now a slight difference according as the one centre or the other be taken, and it was the fact that observations were not falling into strict line with calculations that started Drayson on his research.

I think we are now in a position to apply this astronomical discovery of Drayson's to my prehistoric work.

It will be in the recollection of most of you that in my paper on the "Chronology of the Stone Age," publisher in the first number of our "Proceedings," I claimed that I had evidence of a series of recurrences of glacial conditions in this part of the world during the Neolithic period. I gave the evidences for at least seven such recurrences, which appeared to work up rather rapidly to a climax of intensity and then to work gradually down until the final ice-sheet, which, judging from the amount of striation on the recently-chipped flints, was of very slight intensity. I attributed these glaciations with their waxing and waning in degree to the increase of the ellipticity of the earth's orbit and its then gradual decrease, until it became what it is to-day-an ellipse but little removed from a circle. Astronomers and geologists combined to deny the validity of such change in the orbit as the cause (at any rate, the sole cause) of such great climatic changes. The curious waxing and waning of the degree of glaciation as measured by the amount of striation on the flints concerned nevertheless fitted in up to a certain point with this hypothesis, which, as you all know, we owe to Croll. But I myself was puzzled by the fact that Croll placed the end of the last phase of high ellipticity as long ago as 100,000 years, and it seemed very difficult to place my last class of scratched Neolithsthe class I called No. 6, anything like so far back as that remote period. I have already referred to this difficulty, and to the way in which it is increased by taking an average of the number of scrapers (for instance) that are obviously altogether post-glacial, and of those that have evidences of having been made prior to the last phase of glaciation. But we have seen that Drayson claims that there were conditions that might easily give rise to glaciation not more that fifteen thousand years ago-probably less, for that was the time of the height of this phase of glaciation. The Swedish geologists now claim that they have distinct evidence in their country of a glaciation at that time, in fact that the site of Stockholm was so recently as that date under ice. Therefore I am quite justified in believing that it was to that period that we have to date my last Neolithic glaciation. In this country it was obviously on a very small scale, much smaller than further north, e.g., in Sweden. This ice-sheet in these very recent times was, in every probability, due to the increase in the obliquity of the earth's axis as above described.

If I have made myself clear in my descriptions of the Drayson position it will be at once evident that a return of glaciation will have occurred every time that the obliquity approached and passed through its maximum, and as this took 
place with every revolution of precession, we ought to find evidence of these recurrences with every precession period (which I will take from Drayson as 31,700 years). I maintain that we have the evidence of a certain number of recurrences-seven at least during the Neolithic period.

If the Drayson position as regards the centre of secondary rotation be correct, and if this be the cause of glaciation, why do we see the waxing and waning of glacial intensity to which I have referred? I can find no answer to this question except by the invocation again of increased ellipticity of the earth's orbit, with, perhaps, as a secondary result, a change in the position of Drayson's centre of secondary rotation. Although it may be true, as Professor Culverwell and others have tried to prove, that the mere increase of ellipticity, whereby the relative distances of the earth from the sun at perihelion and aphelion are increased from the million odd miles of the present day to fourteen, fifteen, and even seventeen millions of miles, may be insufficient of itself to cause glaciation, yet it stands to reason that this great increase of distance must do something to modify the amount of heat received by the earth, and that, therefore, it shall come in as a secondary cause of glaciation, almost equal in importance to the primary cause. If Drayson's centre remained permanently the same, and the distribution of land and sea remained practically the same (as it would do in the relatively short periods of precession), then the recurrent glaciations due to it ought to be the same over a very long series of precessions. Yet this is not in any way the case. The last series of some seven glaciations shows great variations of intensity. Behind that we arrive at a period when for a time that must almost certainly have included several precession periods, we have almost no evidences of glaciation. Behind that, again, we have the gigantic Würmian glaciation, which in its turn was only the last of a series of great glaciations. Behind these, again, we have the great " boulder-clay" glaciations, glaciations on so vast a scale that they are known the world over as "The Great Ice Age." How can this be accourted for? Can any explanation be found for these tremendous climatic changes with such knowledge as we have, or as some of us may think we have?

I believe that something may be done in the way of explanation. At any rate, I think that a certain degree of speculative enquiry is justified. Without this it seems to me that we shall never make any advances in our knowledge of these abstruse matters. Additions, notable additions, will doubtless be made to our knowledge in the future; corrections will have to be made in our deductions from such knowledge as we already have; but we may perhaps help in marking out the line of country that will have to be followed.

It seems to me that the Drayson theory clears up the problem of Neolithic glaciations. With the centre of secondary 
rotation in the position assigned to it by him, we have the Arctic Circle descending at intervals of 31,700 years to the latitude of Durham. Each time that this happens there will be a great increase in the cold of the winter. True, at the same time the Tropic comes up to Gibraltar, and therefore there ought to be a great increase in the heat of the summer. But, paradoxical as it may seem, this by no means follows. The aceumulation of ice from the Pole to the Arctic Circle and beyond; the covering of the North Atlantic with icebergs and floes, will have the effect of condensing the vast quantities of vapour that would come up from the mid-Atlantic under the action of the hotter sun, due to the extension northward of the Tropic. It might well happen that the sun would never shine the summer through in these latitudes; at any rate its power would be greatly mitigated. We have ourselves experienced this summer the effects of an exceptional amount of ice in the Atlantic. Yet this is probably a mere trifle compared with what would happen under conditions of far greater intensity. I was recently reading in a book on the "Making of a Great Canadian Railway," an interesting account of a visit to the Northern territories of Canada. The position was somewhat South of Hudson's Bay. The author described how, in the dense primeval forest, he found in the hottest part of summer great lumps of ice just below the surface of the ground. In clearings not far away the temperature was $100^{\circ} \mathrm{F}$. in the shade, and nearly as great at night as in the day. Yet the mere shade of the trees was sufficient to prevent the sun's heat from penetrating through so as to melt ice that had the protection of a thin layer of dead leaves, etc. If a thick canopy of trees can have so marked an effect, the dense clouds and mists that would enshroud lands close to or within the Arctic Circle under the conditions postulated, would have an even greater effect.

This drawing near of the Arctic Circle and the Tropic is a state of things that no one has ever gone into. From the point of view of glaciation it must produce some very strange effects. The fight between sub-arctic and sub-tropical conditions would be much greater than anything we see to-day; and there must have been a very definite line delimiting the sub-arctic conditions, beyond which the sun would hold far greater sway, where the summers would be intensely hot even though the winters were cold. My friends sometimes laugh at me for what they call my local Icklingham glaciers. Curiously enough they may be nearer the truth than they think. Localised to Icklingham, no; but localised down to a certain sharply-defined latitude, yes. I can quite conceive that England might be glaciated and the North of France not only free from glaciers but at periods of the year dried up with a fierce heat. The line might even occur in England itself, though this is not very probable.

It would be interesting to follow this subject further. It is, for instance, quite possible that some of our difficult patination 
problems are due to this struggle between great heat and great cold. One point may be noticed: the rapid disappearance of glaciers when the sun perhaps rather suddenly got the upper hand. I have long thought that the evidence pointed in the direction of the rapid melting of glaciers in countries like our own. On the Drayson theory this would be practically inevitable.

There is one more observation to make at this stage, viz., a reference to the aphelion and perihelion positions in the precession movement. ${ }^{*}$ At the present moment aphelion in the Northern Hemisphere corresponds very closely with midsummer, the earth being in aphelion on July 3rd, whilst midsummer as we all know is on June 21st. Perihelion is on January 3rd, mid-winter or the shortest day being on December 21st. As the precession movement is retrograde these dates will approximate still more closely 320 years hence, when obliquity is at its lowest point, the summer solstice, so to speak, of the precession year. When the other solstice of the precession year is reached, and the obliquity has arrived at its highest point, the exact opposite will occur, and the Northern Hemisphere will have its winter in aphelion and its summer in perihelion. At present this is not a matter of great moment, as the aphelion and perihelion distances from the sun differ from one another by little more than 1,000,000 miles-slightly over $1 \%$. But it would obviously be different when the ellipticity of the orbit has reached a much higher point, and the difference between aphelion and perihelion distances is as much as $14,000,000$ of miles, as in the last period of high ellipticity, or $17,000,000$ of miles, as in the penultimate period. Then the Northern Hemisphere, with its winter in aphelion at the time of maximum obliquity, would feel the effects more than the Southern, and be more exposed to glaciating conditions.

In the present degree of ellipticity both poles would be exposed to very similar conditions at times of high obliquity. For every ton of ice added to the Arctic Circle a corresponding ton would, in theory, be added to the Antarctic Circle. Difference of land distribution and other details belonging to physical geography might modify this to a slight extent, but for our purposes it may be taken as a fairly correct statement.

When, however, the degree of ellipticity is high, then the hemisphere that has its winter in aphelion in the stage of high obliquity (the Northern in the present instance) will accumulate ice at a far greater rate than the one with its winter in perihelion at this same stage of precession. The area within or near the Arctic Circle will greatly increase its degree of glaciation, whilst on the other side of the globe the tendency will be in the opposite direction.

I lay stress upon this point because we at once get a modification of the conditions originally postulated. In an earlier

* Aphelion = greatest distance of the earth from the sun, Perihelion $=$ least distance of the earth from the sun. 
part of my paper I implied that the position of Drayson's centre of secondary rotation (precession) was due to the greater weight of the land in the Northern Hemisphere, as compared with that of the Southern. This was Drayson's contention, treating the earth's movements as those of a delicate gyroscope which responds freely to apparently slight modifications of weight. But what is true of the land surfaces and of the solid substratum on which they rest will, of course, be true of any additional weight placed on one hemisphere and not on the other. We saw that with the present low degree of ellipticity very little inequality of weight by the addition of ice would take place at the time of high obliquity. With high ellipticity this approach to equality in the two hemispheres disappears, the Northern having a far greater addition than the Southern. If the greater part of the area within the Arctic Circle becomes glaciated when the Arctic Circle comes down to a latitude of $55^{\circ}$, we have a circular area $70^{\circ}$ in diameter more or less subjected to the glaciating influences; this means an area with a diameter of 4,800 miles. Put into square miles it amounts to about twenty millions. We have of course no means of knowing what the average depth of ice over this vast area would be, nor even how much of it would be permanently glaciated. But it is quite easy to understand that the weight of ice involved would be enormous absolutely, and relatively not negligible when dealing with the movements of a body so quickly responsive as a gyroscope. The conclusion seems inevitable that Drayson's centre would move, and move appreciably. Further, it seems inevitable that this movement would tend to increase the force of the conditions tending to glaciations by removing Drayson's centre still further from the pole of the ecliptic, and thus bringing the Arctic Circle still further towards the South.

This movement would begin to be appreciable at some point in the ascending scale of ellipticity, and would continue to increase so long as the ellipticity continued to increase. We should therefore have a series of glaciations steadily increasing with each precession period until the point of highest ellipticity was reached. As the ellipticity decreased the opposite results would occur. Drayson's centre would gradually approach the pole of the ecliptic until, with the establishment of a low degree of ellipticity, any ice formation would be practically equal in the two hemispheres, and we should reach the normal condition due to the inequality of land alone. This is the stage in which we now are.

From this it would seem that at the present time Drayson's centre is nearly at its minimum distance from the pole of the ecliptic, but that under conditions of high ellipticity this distance would increase. An increase of a degree would mean during high obliquity a southing of the Arctic Circle to the extent of about 140 miles, and a corresponding movement North of the Tropic. The struggle between Arctic and Tropic conditions would be 
intensified and some remarkable climatic conditions would result.

A question arises which I can state but can make no attempt to answer, yet I believe, in view of some of our undoubted facts, it is one of great importance. It is this : Drayson's centre has in this paper been described as situated $6^{\circ}$ from the pole of the ecliptic, or $29^{\circ} 25^{\prime}$ from the pole of the earth. This gives its declination or latitude. I have given reasons above for believing that it may vary its position in latitude. Can it also vary its position in right ascension or longitude?

Taking the earth as a gyroscope, we saw that it had the primary gyroscopic movement round its axis; it had the secondary gyroscopic movement of the axis itself, producing the phenomenon of precession. Can it also have the tertiary movement of the gyroscope, that resulting from a movement of its centre of secondary rotation in right ascension or longitude? In other words, is the centre fixed in longitude, or does it, in its turn, circle round the pole of the ecliptic? The question is an important one from our point of view. If it be fixed longitudinally in its present position, the Northern Hemisphere will always have its winter in aphelion during the period of high obliquity. If it circles round the pole of the ecliptic, then there would be periods when it would be the Southern Hemisphere that had its winter in aphelion, and some of these periods would certainly coincide with the periods of high ellipticity. Under these circumstances we should have conditions established the exact reverse of those occurring when, during high ellipticity and high obliquity, the Northern. Hemisphere had its winter in aphelion. Large masses of ice would form in the Southern Polar regions unbalanced by similar masses in the North Polar regions. These would tend to counteract to some extent the overplus of land in the Northern Hemisphere; Drayson's centre would approach nearer to the pole of the ecliptic, the Arctic Circle and the Tropic would retire towards the North and the South respectively; the Northern winter would be in perihelion, its summer in aphelion, and for a period embracing several (perhaps many) precessions warmer weather conditions would obtain.

There is probably no means of knowing by astronomical observation whether this really takes place. The period of this tertiary rotation would almost certainly be a very long one, running up into hundreds of thousands, perhaps a million or more years: If it is difficult to detect the exact nature of the secondary rotation (precession) under present conditions, how much greater would be the difficulty of detecting movements indicative of a rotation with so vast a period! Yet it seems as though such a movement must be inevitable. For a centre of rotation like Drayson's to remain fixed, all the conditions of gravity must remain rigidly fixed. If we had nothing but the solid earth and the ocean to deal with, these conditions would no doubt undergo no change in the geologically short periods we are dealing with. But we have 
to take into account accumulations at intervals of vast masses of ice, sometimes on one hemisphere, sometimes on both. We have no reason for believing that these huge masses of ice are arranged on either hemisphere with any attempt at strict symmetry. We saw that for glaciations to occur, it was essential that the regions glaciated should be protected from the fierce summer heats by thick canopies of cloud and mist. It might very well happenit is indeed practically certain that it did happen-that one side of a hemisphere should be favourably situated for the formation of cloud and mist, and that the other side should have a very much less degree of precipitation. It is well known that Siberia shows few signs of glaciation in the past. It is equally well known that North America shows abundant signs of many glaciations. Here we have a case in point. In times of glaciation in the Northern Hemisphere there would be vast quantities of ice in North America, and little or none in Siberia. Here we at once get an upset in the conditions of gravitation which must influence to a greater or less degree the position of Drayson's centre. This change of position will, however, not be in latitude like that I have spoken of above, but in longitude. Frequent repetition of such a change in successive precession periods in the case of a rotating gyroscope would set up a permanent rotation of the centre of precession movement, and induce the conditions above described.

Certain facts in connection with our study of pre-history point strongly in this direction. Let me take one example. During the "drift" Palæolithic period, when the great gravels containing the implements of that period were formed, there was a series of great glaciations (the Penckian). This series continued to the end of the Mousterian age, which was brought to a close -at any rate, it was followed by-the great Würmian glaciation. After this had passed away a quite difterent régime was established. This régime was notable for the absence of glaciations, at any rate on a great scale; and it lasted through the whole of the Aurignacian, Solutrean, Magdalenian, Azilian, and early Neolithic periods. Many pre-historians will say that we may here be dealing with a few thousand years only. I have already in an earlier part of my paper given reasons for thinking that this is an entire mistake. As regards the Neolithic period, my whole paper is founded on the thesis that many minor glaciations occurred in its course. Behind all these glaciations there was a Neolithic period of considerable-probably great-length. If, therefore, the latest of the periods of the stone Age lasted through many precession periods, is it at all likely that its own early stages, together with four other great periods, with many sub-periods, were all crowded into a few thousand years? To my mind, such a thing is inconceivable. It seems quite certain that after many recurrences of glaciations of great intensity, culminating in the Würmian, a prolonged period of quiescence set in, which was not disturbed until mid-Neolithic times, when a series of minor 
glaciations, waxing and waning in degree, occurred only to terminate a few thousand years ago.

But I am anticipating. Before passing definitely to this branch of the subject let me sum up the rather long astronomical disquisition I have been attempting.

1. The earth acts as a gyroscope with, for its primary movement, the daily rotation round its axis.

2. A secondary movement known as the "precession of the equinoxes" occurs, by which the poles describe circles round their respective ceptres once in 31,700 years.

3 . The centres round which these rotations take place are not situated at the pole of the ecliptic as has always hitherto been taught, but are removed by $6^{\circ}$ from the pole of the ecliptic. This was worked out on astronomical grounds by Drayson.

4. One cause at any rate of this departure from the pole of the ecliptic as a centre is the overplus of land in the Northern Hemisphere. Though absolutely very great, this extra weight is small relatively to that of the whole earth. Very small departures from accurate balance in a gyroscope are, however, sufficient to cause movements apparently disproportionate to the amount of such departure.

5. As a result of this displacement of the centre of secondary rotation, the obliquity of the earth's axis to the pole of the ecliptic is constantly, changing, the extremes differing as much as $12^{\circ}$ from one another. At the maximum of obliquity the Arctic Circle descends to the latitude of Durham, and the Tropic of Cancer comes up to Gibraltar. The minimum is very slightly less than the obliquity of to-day. We are, therefore, at present not far from what may be called the "summer solstice of the precession year."

6. The effect of this marked change in the positions of the Arctic Circle and the Tropic is to induce great climatic changes. A struggle will take place between the heat-producing and the cold-producing conditions. Sometimes one will get the upper hand and sometimes the other. In our own part of the world the contact of warm air loaded with moisture from the mid-Atlantic, with the ice formations of the extended Arctic regions will produce perpetual mist and cloud and heavy precipitations. Hence the powerlessness of the hot summer sun to affect the glaciating conditions. Relatively slight causes would change the balance, ard, in some places, instead of great cold, sub-tropical heat would be experienced, with perhaps tendencies to great dryness or the production of desert conditions.

7. So long as the ellipticity of the earth's orbit remains low, as at present, these conditions would reproduce themselves with every cycle of precession. The relative amount of land surface in the two hemispheres during recent geological times is a constant; any additional weight due to ice in the polar regions would be practically the same, and time after time the same degree of glaciation-when conditions favour glaciation-will occur. If, 
however, the ellipticity increases to a relatively high degree, then the hemisphere which has its winter in aphelion during high obliquity will accumulate vastly greater amounts of ice in the polar regions than the opposite hemisphere, which, with its winter in exaggerated perihelion, would have a reduced glaciation. This difference between the two hemispheres would be increased by the fact that the hemisphere with its winter in aphelion would at the time of high ellipticity have the winter season increased in length, whilst the opposite effect would be produced in the hemisphere with winter in perihelion.

8. This not inconsiderable increase of solid material in the Northern Hemisphere must inevitably tend to increase the distance of Drayson's centre of secondary rotation from the pole of the ecliptic, with consequent increase of the glaciating conditions. If the increase takes place in the Southern Hemisphere, the accumulated ice would tend to counterbalance a part of the surplus of land in the Northern Hemisphere, with consequent diminution of the glaciating conditions. This state of things could only occur if the Southern Hemisphere had its winter in aphelion during high obliquity, when therefore the glaciating conditions in the Northern Hemisphere were already at their lowest.

9. At present it is the Northern Hemisphere that has its winter in aphelion during the period of high obliquity, but at present the question of ellipticity scarcely comes in.

10. I have raised the question whether it has always been the case that the Northern Hemisphere has had its winter in aphelion during high obliquity. This would mean that Drayson's centre is fixed in its longitude. It seems unlikely that it should be thus fixed. Drayson never enquired into this problem, which was altogether outside his cognizance. But in view of some important prehistoric facts it is a question of great moment. It is possible that from the astronomical side it may never be answered. It is only on the assumption of a slow rotation of Drayson's centre that the condition formulated above of a northern winter in perihelion during high obliquity could occur. Yet in dealing with the vast climatic changes of the Pleistocene period its possibility should not be left out of account.

My summing up of the astronomical conditions as interpreted in terms of Drayson's theory has been a long one, but the whole subject is so new and so difficult to grasp that I think I need make no apology for reiteration.

We have now arrived at the stage where my two summaries, that of the prehistoric conditions and that of the astronomical conditions, can be brought to bear upon one another.

At present we are approaching the point of least obliquity; we are also approaching the point of least ellipticity, and the Northern Hemisphere has its winter in perihelion. We are, therefore, in very favourable conditions for human effort. Fifteen thousand years ago the spot where I am writing was under ice. 
I have the evidence of it in thousands of striated human implements and flakes belonging to that period. They are not much striated-two, three half-a-dozen strix. They are not patinated, they are not iron-moulded. They are for the most part of chalcedonic flint of very great hardness, and a single scratch on such flint is a remarkable phenomenon. They form the Class No. 6 in my paper on "Chronology." I gave reasons earlier in the paper for believing they cannot go back further than a comparatively few thousands of years. Drayson gives 15,000 years for the glaciation that striated them. The Swedish geologists give the same figure. I feel that we are justified in placing the men who made them in the interglacial period that preceded that glaciation. In this country the glaciation must have been on a very small scale, and it probably lasted a correspondingly short time.

Rather more than thirty thousand years before the justmentioned glaciation occurred there was another period of high obliquity. Ellipticity of orbit was still low. Have we evidence on flints of the glaciation associated with that period? I think so. There is a large group of flints unpatinated, without ironmould, but for the most part lustrous, which is considerably more striated than the last-named series. I suspect that these are the representatives of that glaciation. Of the glaciation behind that, some eighty thousand years ago, I take it that the group classed as No. 4 in my paper on "Chronology" is representative. These pieces stand quite by themselves and are unlike any others. I have a few hundreds of them from my own immediate neighbourhood; but they occur in very large numbers in parts of Southern Norfolk. They are mostly black, but some of them have a beginning of patina. There is occasional iron-mould, though this is relatively rare. Most of the pieces are highly lustred.

All these groups were evidently associated with small degrees of glaciation, though it would seem that the amount and duration of the ice-sheet increase as we pass backwards. Readers of my paper on "Chronology" may expect me to place the No. 5 period of that paper somewhere in these later groups. I always felt uncertain as to its proper position, but with my present knowledge of patination and of what I may term the pre-glacial Neolithic period-the great and highly-developed Neolithic civilization that I am now convinced preceded any occurrence of ice-sheets in Neolithic time-I have come to the conclusion that this curious period, when the flints were scratched with sand alone, must be placed very far back. All the pieces of this class are patinated a porcelainous white or blue-white, a few being a light blue. They stand quite by themselves; but their affinities are much greater with the early pre-glacial period than with the late unpatinated periods above described. I think it probable that they represent the very earliest onset of glaciation after the long period of quiescence I have more than once referred to. 
We shall see presently that this period of quiescence seems to have been associated at times with the deposit of loess over many parts of Europe, and of sand in this neighbourhood. These are the conditions, therefore, that would be found by the first visitation of ice when the period of quiescence came to an end. This would explain why the pieces scratched by the first glaciation should be so exclusively striated with sand. The peculiarity has always been a great puzzle to myself and to my friends when I have shown them the series. Now it seems plain how this marked peculiarity came about.

We have now gone back through the last three periods of minor glaciation. This takes us to about 80,000 years. At this point we are approaching the time when, according to Croll (after Leverrier), the last period of high ellipticity of the orbit was coming to an end. This period of ellipticity was at its height about 200,000 years ago. Between 80,000 years ago and 200,000 years ago we should have three periods of high obliquity, in round numbers 110,000 years ago, 140,000 years ago, and 175,000 years ago. These three periods I claim to be definitely represented by the three periods classed in my paper on "Chronology" as 3,2 , and 1. The flints classed in these three divisions are very sharply defined from those of any of the later periods above described. Beyond the fact that they are all made of fine chalcedonic flint, there is hardly anything in common between the three earlier series and the three later. These earlier ones are deeply patinated and markedly iron-moulded. The striations are on a large scale, much more numerous and deeper in degree. The flints of the No. 3 class differ from those of No. 2 class in being less deeply patinated on the average, less iron-moulded, with a less proportion of large deep scratches and a larger proportion of sand scratches. Otherwise there is no strongly-marked line of demarcation between them. The No. 1 class is, however, strongly demarcated in every way from any other class, and stands quite alone. It constitutes the rudest and roughest series of Neolithic implements I have ever seen. They are on a par with M. Rutot's Flénusien. The scratching is of an extraordinary nature and quite sui generis.

Behind these come the "old whites," which again stand quite by themselves. The scratching on them is again sui generis and unlike anything else.

There are thus five groups of scratching with sharply-defined characteristics, and at least two other groups which can be separately placed. There is a definite increase in degree of striation as we pass backwards from the latest where the striation is slight to the No. 1 where it is intense. This seems to be the maximum, and behind it come the "old whites." Are there any groups behind these? It is almost certain that there are, but the further we go back the more difficult does it become to be sure of distinctions. I have already mentioned, however, that the conclusion is being forced upon me that the group $I$ had hitherto 
called No. 5, the white patinated pieces with sand scratching only, should really be placed at a very early period instead of a late one, and, as already suggested, it may be that these constitute the very first of the scratched flints when glaciating conditions began to set in during the Neolithic period.

I have laid stress on the very definite groups of scratched pieces, not only on account of the great importance of this evidence of multiple glaciations occurring in mid-Neolithic times, with an increase up to a maximum of intensity, and then a decrease to a minimum of very small degree; but also because I have several times been asked by friends, whose opinion I value, whether the whole series of groups may not have been due to one glaciation. The thing is impossible. A single sheet of ice could by no means have picked out stones of certain sharply-defined characteristics to scratch in certain sharply-defined ways. I venture to think that anyone who should take the trouble to work through my drawers would agree with me that it is unthinkable that such should be the case. The groups I am dealing with are many of them very large, a single group may be composed of one or two or even more thousands of specimens, and as above seen in the case of several of the groups there is nothing in common either in appearance or in the kind of striation between the different groups.

When we pass behind the whole series of Neolithic glaciations what do we find? As I have already said, we come to a series of white patinated flints, many finely worked and many finely polished. In speaking of white patination I said that it appeared to end with the "old whites," one of the earlier of the scratched series. They belong to a period when the glaciations were approaching their maximum severity. After them no white patination seems to have occurred, but before them white patination was the rule until we get back into the latest of the "cave" (Palæolithic) periods. This probably involves a great lapse of time. The early Neolithic period, to judge by the evidence of the stones in my own collection, was itself of great length, but in the absence of striation it is difficult to measure it, as there is nothing to show whether we are dealing with one precession period or several. Patina and iron-moulding come to our assistance up to a certain point. Thus, as I have already pointed out, there is one large series containing many fine implements that is wholly without iron-moulding; there is another large series in which the arêtes are all touched with iron-mould; and a third large series, including a considerable number of finely-polished flint axes, where iron-moulding is present to an extent seen in no other class in the whole of the Stone Age. I have about seventy of these axes, mostly from this neighbourhood, but also from other parts of England and many districts of France. The evidence of these various groups, and other evidence which it would take me too long to go into here, points to the lapse of time on a large scale and to changing conditions, which can 
hardly have been other than climatic. The subject is one of great complexity, about which nothing has been hitherto known.

What is the beginning of this Neolithic period? From what did it take its rise? What is its position relatively to the latest Palæolithic? I confess to complete ignorance; I think I may go further and say that no one knows anything about it. The Maz d'Azil discoveries help us very little. So far as I can judge, the fine polished axes above referred to are the earliest Neolithic flints I have. A year ago I should have said that probably Grime's Graves and Cissbury would come in to fill part of this great gap in our knowledge. The flints from these and allied sites have a pure white patination like the latest of the Palæoliths and the early Neoliths. They yield implements of chipped celtlike forms, which might easily be considered as the fore-runners of the polished celts. But my friend Mr. Reginald Smith has entered a "caveat" against this view; and until we have further evidence his "caveat" must be respected.

On the Palæolithic side we have a definite "cave" floor, with typical Magdalenian implements, entirely composed of flint with pure white patina-the older series from London Bottom, Icklingham. Therefore these white patinating conditions go back as far as the Magdalenian. Then, again, there is another "floor" of undoubted "cave" (Palæolithic) age at Wangford, near Brandon. The exact position of this "floor" in the "cave" series is at present doubtful, but amongst the implements and flakes found on it a considerable number are differently patinated on the two sides, the patinated side being a pearly white and the other black or with a a surface slightly changed. Thus, white patination in a modified degree began at the time the Wangford "floor" was formed; the conditions seem to have reached their maximum for the "Cave" period in Magdalenian times, as represented by the older series at London Bottom; they continue through the earlier Neolithic period and extend down to the "old whites" of that period. Neither at London Bottom, nor at Grime's Graves, nor at Cissbury, nor in any of the similar groups found in various parts of the country does one-sided patination occur. Yet, as I mentioned in an earlier part of my paper, there is more than one series, apparently connected with the Neolithic period, which is distinguished by this remarkable peculiarity. As we have just seen, it is also associated with at least one group of "cave" implements. The patination in these cases runs from blueish-white to white. I have called such patinas sun-patinas; and, as I have already said, there are strong reasuns for believing that all white patination is due to sun action. It seems as though great sun-power was a characteristic of the stages, including the Magdalenian and perhaps just pre-Magdalenian time, through the pre-glacial Neolithic down to the earlier Neolithic glaciations ; but that the action of the sun was finally conquered by the relatively great glaciation represented by my No. 1's. From that time forward it has never 
been sufficient to cause whitening of the flints. At what would seem to have been the very height of the sun-patinating times one-sided patination did not occur, the flints being uniformly burnt white all over; but both before and after these extreme conditions the action of the sun was insufficient to burn both sides equally. There was first a stage in pre-Magdalenian or early Magdalenian time, when the flints were burnt white or blue-white on one side and left unpatinated, or only slightly patinated, on the other; then in later Magdalenian time the flints were burnt a fine white all over; subsequently in early Neolithic times the flints were burnt white all over; then came a time when they were burnt blueish-white on one side and left untouched on the other. After this there was a continuation of the tendency to white patination into the period of the "old whites," and, finally, from that time downwards white patination ceased to occur. This account of what seems to have taken place will no doubt require amplification in the future, as the conditions were undoubtedly complex; but I believe that as it stands it will serve as a basis for further investigations.

It would seem then that during the mysterious period when the last stages of the Palæolithic age passed into the Neolithic, our part of the world was going through a more or less prolcnged experience of great heat. Was there a hiatus between the two? It is impossible to answer at present with certainty, but everything points to the probability of its having occurred. In this region there is no evidence of any passage in situ from the one series to the other. The Magdalenian series at London Botiom are finely-made typical "cave" pieces; the earliest Neolithic show a high development of polishing. Mr. Reginald Smith claims that there is good evidence that even in the "Cave" periods some polishing of flint had been introduced. From pieces in my own collection I should be inclined to agree with him, but I have no evidence whatever that polished celts were produced before the Neolithic. It would seem as thongh the line of development which led to them took place elsewhere, and that Neolithic man came here already in a fairly advanced stage of the new culture.

What then caused the hiatus if such existed? Certainly not ice, for we are evidently dealing with the very opposite condition to an ice-age. My own conviction is that it was due to the onset of desert conditions. There is no sign of any glaciation on the scale even of the lesser glaciations that occurred in Neolithic times. Yet the great "cave" periods had been ushered in by a gigantic glaciation, the Würmian. Whatever the explanation may be, it is very remarkable that this great glaciation was so immediately followed by a prolonged period of profound quiescence, verging into a régime of great heat. I have already uttered a warning against treating this period as a short one. When we see not less than seven precession periods interpolated into the Neolithic as a mere episode in its existence, is it likely that many culture periods, the Aurignacian, the Solutrean, the Magdalenian, 
with all their known sub-divisions (not to speak of those which are sure to be discovered in the near future), and moreover a considerable slice of the Neolithic itself; is it likely, I say, that all this can be squeezed into a few thousand years? We seem, on the contrary, to be dealing with a long succession of precession periods, during which, instead of glaciation, great heat was the predominating factor. What evidence have we beyond that of the white and one-sided patinas already evoked? This: Our chalk country in the East of England is, over many hundreds of square miles, covered with sand to a varying depth, sometimes for as much as fifteen or twenty feet. Whence comes the sand? And further, what brought the sand? An exact answer to the first question would have to be given by a geologist, but we shall probably not be far wrong if we assume that it came from the greensand margin which surrounds the large chalk area. How got it here? I believe there is only one answer-wind, at a time when the eand was loose, uncontrolled by any vegetation. Provided that the vegetation is not interfered with, there is no blowing of sand to-day. For this prodigious spreading of sand to have taken place, desert conditions are necessary. If so, when was this? Dr. Marr, one of our leading geologists, who has specially studied this subject, arrived some time ago at the conclusion that the last spreading of sand took place at the same time that the latest loess was being laid down over Europe, that our latest sand is contemporary with the latest loess. Mr. Reginald Smith, on archæological grounds, came independently to the same conclusion. My own evidence points the same way. Tbe "cave" floor at Wangford is uniformly covered hy a deposit of sand about two feet thick.

I am not qualified to deal with the thorny question of the formation of loess in all its bearings, nor would this be the place to do so. But whether or no our sand corresponds to the upper layers of loess in other parts of Europe, there can, I think, be no doubt that it was wind distributed, and that this wind distribution of the upper layers took place in post-Magdalenian time. The conditions that led to it were probably not dissimilar to those described by Dr. Stein in his books, "Sand-buried Ruins in Khotan" and "Ruins of Desert Cathay." A large tract of country in Central Asia, chiefly in Turkestan and Western China, has become desiccated since the beginning of the Christian era. Many large cities were involved. Tor a time they were able to maintain themselves by irrigation, but since the Eighth Century they have beer abandoned and they are now buried in the sand of a waterless desert. The countries traversed by Dr. Stein seem to be only a portion of a great desiccating belt of great length. Dr. Stein's evidence shows that this drying up process has been taking place for a length of time that, from the geological point of view, is exceedingly short. The finding of Neolithic remains in what are to-day entirely desert parts of the Sahara points to the same conclusion that even the Sahara was habitable, some 
parts at any rate, in what, geologically speaking, are recent times. I believe the causes of this desiccation have never been ascertained; but, in view of the relative rapidity with which they are acting, it would seem as though they are connected with climatic changes due to cosmic causes, glaciations, and the like, rather than to the progress of some general tendency to universal desiccation of the whole earth as time goes on. My suggestion is, that in view of the wide-spread occurrence of white patination about the time, both before and after, of the passage from the last Palæolithic to the earliest Neolithic period, which patination is most probably of sun origin ; in view of the occurrence of one-sided patination, also mainly white and almost certainly of sun origin; and, in view of the fact that sand in great quantities was blown over large tracts of country in Eastern England at the close of the Magdalenian period, which movement of sand on such a scale is only possible in the absence of vegetation; the evidence points to the probability that at the time of the hiatus commonly postulated as occurring between the Palæolithic and Neolithic phases of culture, North-Western Europe was in a stage of desiccation like that now seen in the desert belt of Central Asia and elsewhere.

The question arises whether this was the only period of desiccation, or whether this was merely the culmination of several periods which gradually worked up to a maximum. There is some evidence pointing in the latter direction, for one of the features in almost all the caves that have been excavated with care is the occurrence of "sterile" layers between the "fertile" layers. These sterile layers are often as thick as, perhaps thicker than, the: ertile layers; and the fertile layers above and below a sterile layer rarely, if ever, show the same stage of culture. In a time of desiccation, when the air is often full of sand or other forms of dust, the dust would make its way for a certain distance into the caves, and would gradually form a deposit. It is practically certain that during these sterile periods this part of the world was uninhabitable; these times were in the full "Cave" age; men, both betore and after these sterile times, inhabited caves, where such were available; and it is the height of improbability that time after time the troglodyte was replaced by races that made no use of caves. Only two conditions can be quoted as leading to the absence of man in these sterile times-ice and desert. In this part of the world, East Anglia, there is good evidence that it was not ice that drove the "cave" men out. I maintain that Neolithic man was driven away by ice time after time, but there is no evidence that "cave" man was so driven away, his implements, which occur in considerable quantities, showing no signs of the passage of ice over them.

My suggestion then is that after the great Würmian glaciation which brought Mousterian time to a close, there was a gradual alteration in the tendencies of climatic changes; that instead of 
recurrences of glaciating conditions there were recurrences of desiccating conditions, which culminated at the time of the Palæo-Neolithic hiatus, continued for some time into the Neolithic, ultimately to disappear and to have their place again taken by glaciating conditions. This does not necessarily mean that there were not very cold interludes during desiccation. The climate would probably be like that described by Dr. Stein as ruling in his desert countries, winters so cold that exploration was difficult, summers so hot that exploration was impossible. This would apply to the times of full desiccation; in the intervals there would be every variety of steppe conditions. Through the whole period, however, it would be steppe conditions that had the mastery.

How long did desiccation render these countries of NorthWest Europe uninhabitable? Was it for a part only of a precession period, or was it for several precession periods in their entirety? An answer is obviously at present impossible. We only know that time after time man returned with forms of culture, which, while differing from one another, yet had many points of resemblance_species of the same genus, so to speak. Then after a blank there came a man of another genus. His coming corresponds to a time when the evidence is in favour of a culmination of heat conditions with resulting dry conditions. These would be more far-reaching in their effects than glaciation. The latter implies at any rate deposition of moisture. When the glaciation passed away there would be all the moisture necessary for regetable growth. The passing of the heat-producing causes on the other hand by no means leads necessarily to the passing of the causes leading to drought-a cold desert is as bad as a hot desert. It might well be that when desiccation was at it height, these regions were uninhabitable for several precession periods. Hence the great change in culture when man finally came back.

I think we are now in a position to bring the two lines of enquiry, astronomical and prehistoric, into juxtaposition, and to see to what extent they fit in with one another.

On the astronomical side we have-

1. Precession movement round Drayson's centre, situated $6^{\circ}$ from the pole of the ecliptic. Period 31,700 years. Result: Cyclical variation of the positions of the Arctic and Antarctic Circles and of the Tropics.

2. Revolution of Drayson's centre round the pole of the ecliptic. This is not postulated by Drayson, but it would appear to be inevitable. Period unknown. Result: Gradual change in the relative positions of summer and winter in perihelion and aphelion.

3. Changes in the degree of ellipticity of the earth's orbit. Period very variable. The last period of high ellipticity began about 300,000 years ago and was rapidly diminishing 100,000 years ago. The pen- 
ultimate period began about $1,000,000$ years ago, and after great oscillations rapidly ended about 700,000 years ago. Result: To accentuate the winter conditions of the hemisphere with its winter in aphelion. To moderate the winter conditions of the hemisphere with its winter in perihelion.

At the present time the obliquity of the axis has almost reached its lowest limit; the eccentricity of the orbit has almost reached its lowest limit; winter in the Northern Hemisphere takes place while the earth is in perihelion, exact perihelion and the winter solstice being almost simultaneous. The conditions are, therefore. extraordinarily favourable for human existence in many parts of the hemisphere.

Let us consider the position of high obliquity, low eccentricity, and winter in aphelion in the Northern Hemisphere. This took place 15,000 years ago. We now have the claim of the Swedish geologists that Southern Sweden was under ice at that time. The latest of my Neolithic glaciations for this part of the world would fit in admirably for this date. I gave reasons for believing that this glaciation could not be very far back. So, having Drayson's assertion on astronomical grounds and the Swedish assertion on geolngical grounds, I have no hesitation in placing my last glaciation on prehistoric grounds at that date.

We have thus a good measure for the amount of glaciation that would be caused by the above association of conditions. Here it was on the smallest possible scale, and without the writing on the flints we should certainly know nothing about it. Still, the smallest possible glaciation is a remarkable phenomenon in itself, very far removed from anything seen to-day away from Greenland or Spitzbergen.

For the moment I am leaving the other Neolithic glaciations on one side. We can deal with them better after making some attempt to arrive at the unknown period of revolution of Drayson's centre round the pole of the ecliptic. I said that Drayson himself had never postulated this movement. There is reason to believe that he suspected it, but it is one that it is probably impossible to detect by astronomical observation carried on for short periods only. The effect of it would be, as already stated, to bring sometimes summer and sometimes winter of the Northern Hemisphere into aphelion at times of high obliquity. Therefore, at some past time, instead of the northern winter being in aphelion at the maximum of obliquity as at present, winter would be in perihelion at that stage of precession and summer in aphelion. With low ellipticity, as now, this is of little consequence; but with a much higher ellipticity than now obtains, it is a matter of the utmost consequence, and glaciation in the Northern Hemisphere would be greatly reduced or even disappear altogether. The tendency would be for its place to be taken by great heat with not improbably belts of great dryness, which might amount to total desiccation. I pointed out that such conditions seem to 
have occurred at about the time of the passage from the Palæolithic to the Neolithic stages of culture. White patinations were then the rule, both at the end of the Palæolithic and in the early Neolithic; and both before and after the phase of white patination one-sided patination seemed to occur. At that time also sand was extensively deposited in these parts, and windconveyed loess was widely spread over many parts of Europe.

It would thus seem that here we have the conditions produced by the combination of high obliquity, high ellipticity, Northern winter in perihelion. When did this happen? I believe about half a million years ago. If we take Croll's chart of the varying ellipticity for the past one million years, ${ }^{*}$ we find that there was a period of recurrent high ellipticity beginning about three hundred and fifty thousand years ago and ending about seventy thousand years ago. This is the period occupied by the seven (or more) glaciations associated with Neolithic time. Of these I shall speak presently. There is abundant evidence in my own collection of a long Neolithic period before this-the early Neolithic period. Therefore we have to allow a long time before the setting in of this régime of high ellipticity for the Neolithic period. Half a million years ago there was a time of moderately high ellipticity, and I think that this may well be associated with the conditions enumerated above, which led to conditions of desiccation with extreme variations of heat and cold. We cannot be very far wrong here, for the recurrent Neolithic glaciations have given us the clue to the scale of time with which we are dealing in the Neolithic.

This would mean that Drayson's centre male half a revolution in 500,000 years; consequently a full revolution would take a million years.

The full revolution would bring us back to the same relationship of the Northern seasons with perihelion and aphelion; winter during high obliquity would be in aphelion, and in case of high eccentricity glacial conditions would be permanent. What do we find? A million years ago the earth was entering upon a series of eccentricities of quite exceptional height; there were three maxima with two intervening minima, the whole period lasting for about three hundred thousand years. We have then a recurrence during these three hundred thousand years of conditions most favourable for glaciation; high obliquity, winter in aphelion, and high eccentricity. I believe that the three great glaciations of Professor Penck, the Mendelian, the Rissian, and the Würmian, may be attributed to these three maxima. As the Würmian is well known to be post-Mousterian, this phase of culture would fall into the period of minimum eccentricity, that immediately preceded the last of the great maxima. The northern winter by this time was, however, not strictly in aphelion. Treating true aphelion as the winter solstice of the

* This is reproduced in Fig. 1 , from the diagram is Croll's "Climate and Time." 
great period of revolution of Drayson's centre, mid-winter of the Northern Hemisphere would, at the beginning of the Würmian eccentricity, fall about the end of the month of February, so to speak, of this great year.

The phase of high ellipticity which I have associated with the Würmian glaciation, after lasting from start to finish for about 100,000 years, ended in a period of relatively low elliptscity, slightly greater than that of to-day. This was about 700,000 years ago. By this time the great year of revolution of Drayson's centre would, from the point of view of the Northern Hemisphere, have reached the analogical position of the end of March. The Northern Hemisphere would therefore be in a favourable position for throwing off permanently the great glaciation from which it had suffered intermittently during the previous three hundred thousand years. Eccentricity was low, and the winter of the Northern Hemisphere occurred about mid-way between aphelion and perihelion, the advance being towards perihelion. It would therefore be in a better position than at the present day at the recurrence of high obliquity. To-day, as we have seen, high obliquity is associated with the northern winter in full aphelion; yet, under these circumstances, the last glaciation in these regions was on a very small scale. As, however, in both cases, in post-Würmian time and in the most recent phase of high obliquity, ellipticity has been low, the difference between the two could not be great. At any rate, if glaciation occurred in immediate post-Würmian time, it must have been on a small scale. From that time onwards the conditions improved, until the northern winter during high obliquity about 500,000 years ago was in full perihelion. Ellipticity all through this period was moderately high on the average; but the resultant of the conditions present would be against northern glaciation and in favour of the production of dry periods. This was the time of those "cave" periods that followed the Mousterian, culminating with the occurrence of winter in full perihelion to which I attribute the hiatus between the Palæolithic and Neolithic periods.

We now pass the "Summer" solstice of the "great year" and approach the later "Summer" months $-500,000$ to 400,000 years ago, and from the latter to 300,000 years ago. Without going into details of ellipticity during these 200,000 years, conditions would tend to modify as the Northern winter during high obliquity passed away from full perihelion. It will be easily seen that each "month" of the "great year" postulated would amount to about 85,000 ordinary years; therefore, if $\mathbf{5 0 0 , 0 0 0}$ years ago the great year was at its Summer solstice, say, "June 21st," 200,000 years later we should arrive at the beginning of "September." About that time began the last great period of high ellipticity, and we should therefore expect that the climatic conditions arising from it should show some curious modifications resulting trom the struggle between the cold conditions and the dry conditions associated with high ellipticity 
I shall not attempt here to correlate this state of things with my series of flints, though I have large series of "early Neolithic" implements which fall clearly into the period anterior to the rise of ellipticity. Exactly when man was able to come back again after the desert conditions postulated for the hiatus it is not possible to say; but he was evidently here for a long time before cold conditions again began to interfere with him. His implements seem to have patinated almost uniformly white at this time, and whiteness continued more or less, as I have repeatedly said, until the "old white" period, which is early in the glaciating times.

Meantime ellipticity was increasing and the "great year" of the revolution of Drayson's centre was advancing into full "Autumn."

We now come to the Neolithic glaciations which occupied this period of high ellipticity, and which recurred time after time until, geologically speaking, recent times; that is to say, the last recurrence was 15,000 years ago, during the period of high obliquity belonging to the precession cycle in which we now are. This question of Neolithic glaciations is the crux of the whole matter; they are, geologically speaking, quite recent; there has been no great disturbance of the topography of this part of the world since they occurred; but in certain places, of which Icklingham is one, evidences have been left behind by them which can be studied in large quantities and at leisure. It is through the study of these evidences on the flint that we get the time factor which gives the clue to the chronology of the Stone Age.

It is certainly difficult to convey to others the full force of these contentions. I have myself been closely studying the evidence for many years past. I know all the salient points intimately, the various groups of flints are as familiar to me as the faces of my friends. I know also the difficulties of the study. I am fully aware that I have not got to the end of it yet, but every year adds to my knowledge, and adds also to the sureness with which one threads one's way through the labyrinth. But I can well understand the amazement and the perplexity with which my friends survey the many series I place before their eyes. It is impossible that it should be otherwise. The whole story is so entirely new, the great drafts upon.time stagger the mind, the upset of all our preconceived notions is so complete, so revolutionary. I am sometimes tempted to keep the whole thing quietly to myself, going on with my work and leaving it to the next generation to fight the matter out. Thirty or fifty years hence much will be evident which is to-day shrouded in the deepest obscurity, and many of the problems I am now struggling with will clear up almost of themselves. I believe, however, that I should not be doing right in holding my peace. What at first were unformed suspicions have now grown into profound convictions. I am handling my evidence every day-almost every day adds to the quantity of it, and I believe I am right in bringing it forward. 
I say this with a view to impressing you with the enormous importance I attach to these evidences of Neolithic glaciations. So far, I have been able to detect seven recurrences, and it is almost certain that there were one or two more. As I have said, the last and least of them was 15,000 years ago, and the length of time between the height of each glaciation was, according to Drayson, 31,700 years - rather less if we take the cycle generally accepted by astronomers. Six recurrences behind the last would give us about 190,000 years - which, with the 15,000 years that have elapsed since the last, gives us rather over 200,000 years. This takes us back to the extreme height of the last phase of high ellipticity, it also takes us back to the " old whites," or perhaps the No. I's of my scratched series, both of which give evidence of the maximum amount of glaciation. The ascent to this high degree of ellipticity was rapid, but it had been preceded by a phase of moderately high ellipticity, which belonged to the same group. I have but little donbt that certain series of scratched stones of early date are connected with this first phase of the group, but I am content, at present, to attribute the seven series of scratched stones with the period of 200,000 years, dating from the maximum of ellipticity to the present day. These series show the steady diminution of degree and length of glaciation which we should expect with the diminution of ellipticity. This I pointed out in my first paper, but the addition of Drayson's variations of obliquity completes the picture, which without this aid was unconvincing. The subject, as will be appreciated by all of you, is of the utmost complexity. I have done my best to explain its various phases to you, but no one knows better than myself how wholly inadequate my treatment of it has been.

\section{Synopsis of Astronomical Years Postulated.}

1. Ordinary Year, revolution of the earth round its orbit.

2. Precession Year, revolution of the poles round Drayson's Centres, removed $6^{\circ}$ from the pole of the ecliptic.

Period 31,700 ordinary years. Pendulum movement of the earth's obliquity, with consequent changes in the position of the polar circle from $35^{\circ} 25^{\prime}$ to $23^{\circ} 25^{\prime}$ Present obliquity $23^{\circ} 27^{\prime}$

Minimum obliquity 320 years hence (summer solstice of Precession Year).

Northern winter in perihelion during low obliquity.

" " aphelion " high "

3. "Great Year" of the revolution round the pole of the ecliptic of Drayson's centres.

Perrod about $1,000,000$ ordinary years.

Result. Gradual change in the relative positions of the seasons to perihelion and aphelion. At present the Northern winter during high obliquity takes place in 
aphelion. 500,00 years ago the Northern winter during high obliquity took place in perihelion. A million years ago the Northern winter in high obliquity took place in aphelion.

\section{[POS'TSCRIPT (JuNE, 1913).]}

Since this address was delivered, a discovery has been made at Icklingham that throws some light on the subject of implements and flakes with one-sided patination. In one of the fields which form part of the small central valley that was described in my paper on "Chronology," in the first part of the "Proceedings" of the Society, and which is one of the principal sites containing large numbers of scratched neoliths, trenching operations were entered upon in February of the present year. The digging was carried "two spades deep" in the same way as was done on the estate some miles away, from which so many pieces with one-sided patination were brought to me by the labourers. The part of the field thus operated on was close to the ridge dividing the central valley trom the western side valley. It was therefore only a few feet lower than the highest ground in the neighbourhood. In common with the land for many miles round in every direction, the field is covered by sand resting upon a chalk basis. Little was known as to the depth of the sand, as the plough never touches bottom, and there has been no deep digging on an extensive scale in the district. When the men had trenched this higher portion of the field they found that in many places they got below the sand and on to the broken top surface of the chalk (dead-lime) within eighteen inches, though in other places the chalk was not reached at four feet (holes specially dug for sounding purposes). In several places on the field they got down on to what was evidently a "floor" where implements and flakes in large numbers were lying together, and where the soil was blackened by the presence of charcoal. A remarkable point about these implements and flakes-some two hundred in number-was that the great majority were patinated on one side only, and in the case of those that were patinated on both sides, one side was much more so than the other. The patinas were similar to those with which I was familiar on the pieces that had been brought to me in large numbers from the neighbouring estate, a few miles away, referred to in the early part of my paper, and which had started me on the research into this question of one-sided patination. None of the pieces were iron-moulded, none of them were striated, and none were lustred. When we come to the question 
of the nature of the implements, we are met by this strange fact that three of them, so far as their shape goes, might have come from palæolithic gravels. One is a large ovate-lanceolate implement, 9 inches long, recalling the "limande" of the St. Acheul deposits (Plate LXI., Fig. 1); another is a pointed implement with thick butt, $5 \frac{1}{2}$ inches long, showing a close resemblance to well-known gravel types (Plate LXI., Fig. 3); a third is a pointed ovate, $3 \frac{1}{2}$ inches long, of a pattern practically identical with those from the Warren Hill gravels (Plate LXI., Fig. 2). All of these show one-sided patination, the patina being the peculiar blue and white generally associated with this condition. With these three implements, so very unusual for a presumably neolithic deposit, lay a chipped celt with parallel sides, of the type so familiar as coming from Cissbury; some long rough flakes, the two longest being respectively $8 \frac{1}{2}$ and 8 inches; and a considerable number of very fine scrapers, chiefly round in shape and of exceptional thinness. One of these is $3 \frac{3}{4}$ inches in diameter. Large, more or less round scrapers of exceptional thinness occur amongst the pieces with one-sided patination brought in from the neighbouring estate. Other implements were also found on the "floor" which recalled those of the later (presumably Neolithic) series at London Bottom, Icklingham. (Plates LIX., LX., and LXII.)

What is the period of this "floor"? The answer to this question is important from several points of view. We are evidently dealing with a fine series of implements, showing an association differing from anything that has, I believe, ever been described. In the next place, the civilization represented by it was evidently wide-spread, at any rate in East Anglia, for I have specimens which clearly belong to it, not only from the district some miles away, from which my early pieces were brought, but also from the neighbourhood of Grime's Graves, 15 miles away (Plate LX., Fig. 2); from Cranwich in Norfolk*, some 25 miles away due north (Plate LX., Fig. 3); and from Aspall, in Mildenhall Fen. Finally, the position may claim to have some geological significance, since the floor is uniformly covered by a coating of sand from 18 inches to 2 feet in thickness, which has obviously been deposited since the pieces were made. I was not present when the first series, including most of the larger and finer specimens, was discovered, but the men assured me that they were lying on the broken chalk surface; they were at any rate in the deeper layers of the sand, which also contained pieces of charcoal, débris of the old hearths. I was, however, present when a second large find was made. Here the pieces were lying under the same depth of sand, but there was also sand beneath therr; for it was found in further digging that the floor in this spot lay over a large "pot-hole" in the chalk, which was excavated for

* I am indebted for the gift of a very fine specimen from this locality to the kindness of Mr. J. S. Warburton, of Methwold. 
some 10 feet down without reaching bottom. The pot-hole was filled with sand, which must have been there before the men of the "floor" occupied the site.

I believe that the "floor" is of Neolithic age, but if so it is a sub-period of the Neolithic, which would seem to be new to science. The association of large, finely-chipped implements, strongly suggestive of the Palæolithic period, with very finelymade scrapers of Neolithic aspect, all with the same peculiarities of patination, is an unusual occurrence. The resemblance of the larger pieces is, however, not to the later "Cave" periods, but to the "Drift" period of the Palæolithic; the scrapers and other smaller pieces are, on the contrary, of Neolithic forms. Their close juxtaposition and the similarity of patina prove conclusively that the larger and smaller pieces are approximately of the same date. No polished piece occurred amongst the series unearthed on the field at Icklingham, but amongst the pieces brought in from a few miles away is a scraper closely resembling those found in that field both in shape and in patina, which is remarkable in that the unpatinated bulbar side is artificially polished in the neighbourhood of the bulb. So far as my knowledge goes, this is unique. I have many thousands of scrapers in my collection, and amongst them are three specimens that have been slightly polished on the chipped upper side, but this is the only instance in which there is polishing on the bulbar side. It is strange that this unique feature should occur on a scraper that is a fine example of one-sided patination, and which might be selected as a type specimen of the series. There is also slight polishing on the upper patinated side, and it is noteworthy that the polished portions have taken the same patina as the unpolished surfaces. I have no wish to claim this piece of evidence as conclusive, but I think we may allow that it carries considerable weight.

As regards the association of the large pseudo-Palæolithic implements with some division of the Neolithic period, jt should be borne in mind that there are several periods about which very little is at present known, but to which attention is being drawn by prehistoric archæologists. There is the group (or groups) associated with the names of Grime's Graves and Cissbury. There is the later series from London Bottom, Icklingham; and there is the series from Peppard Common in the Chiltern Hills, discovered by Dr. A. E. Peake. I have already in my address referred to the fact that Mr. Reginald Smith has recently brought forward some evidence in favour of the thesis that Grime's Graves and Cissbury should be referred to the Palæolithic period; but the attribution has by no means been definitely settled, and in the present connection the pieces from those sites must not be left out of account. One feature present in all the series that $I$ have mentioned is the occurrence of large chipped implements. From none of them, so far as I am aware, have come pieces comparable with the pseudo-drift implements from the Icklingham field; 
and in none of them does the large finely-made scraper bear so marked a proportion to the other implements; indeed, in the later series from London Bottom the scraper is conspicuous by its absence. But in all of them there is the same tendency to the production of great chipped implements. The subject is a highly complex one, and will require further discoveries for its complete elucidation. For the present all that can be said is that there is evidence for the existence of a whole series of sub-periods in the early Neolithic, in which a prominent characteristic is the making of large and somewhat rough chipped implements. As regards the relationship of the Grime's Graves period and that of the series with one-sided patina on the "floor" of the Icklingham field, we have this evidence: In the immediate neighbourhood of the flint pits at Grime's Graves are found large, more or less circular, roughly-chipped blocks weighing up to 3 or $4 \mathrm{lbs}$. They are patinated all over a dead white, without iron-moulding, without scratching, and with little or no lustre. Those familiar with the material from the neighbourhood of Grime's Graves will at once recognize the description. Exactly similar pieces come from Cissbury. Now, in the Icklingham field the deep trenching that exposed the floor under discussion also threw up one of these large circular chipped blocks, uniformly patinated dead white, without iron-mould, scratching, or lustre. (Plate LXIII., Figs. 1 and 2.) Two small pieces of the same type were also thrown up. There can, I think, be no doubt that these are of Grime's GravesCissbury age; and there can be little doubt that they are older than the pieces with one-sided patination on the same floor. Therefore, the conclusion seems justified that in the chain of sub-periods that make up this portion of the early Neolithic the Grime's Graves-Cissbury group is earlier than the groups with one-sided patination. The earlier group, moreover, was exposed to the conditions producing white patination either for a longer time or the conditions were more intense than was the case with the group with one-sided patination. Not improbably both modifications were present.

We now come to the geological side of the find in the field at Icklingham, for I maintain that it has a geological aspect. We are undoubtedly dealing with a "floor"; for not only are the implements and flakes with this peculiar one-sided patination found lying together, but they are associated with the charcoal resulting from the hearths of the men who made them. Moreover, this "floor" has not been disturbed since the ancient days when men were living on it. Yet this "floor" is uniformly covered by a pall of sand too deep for the plough to reach through it, which seems to be part of the general pall of sand covering the whole district. Yet, in or on this sand are vast numbers of human implements and flakes of a character wholly distinct from those found on the "floor." These implements and flakes have their own special patinas, are almost invariably lustred, a large number are iron-moulded, and a very large 
number scratched; for this is one of the fields that have supplied many of my best specimens of striated flints. The conclusion seems inevitable that the flints on the undisturbed floor are older than the flints on or near the surface that have been turned up by the plough, and that the pieces with one-sided patination are older than the striated flints. After the making of the former, and before the making of the latter, a pall of sand was spread over the whole surface. I maintain that this could only have happened under desert conditions, for apart from recent disturbance of the soil, no sand blows in districts under vegetation. Therefore at the end of the group of Neolithic sub-periods which culminated in the typical series of flints with one-sided patination but without lustre, iron-moulding, or striation; and before the great group of sub-periods with striated flints, there must have been a Desert period with extensive sandblowing. This was the last of the Desert periods, but it was quite certainly not the first, for at one place, as we have seen, the "floor" lay over a deef pot-hole filled with sand. It is at present not possible to say how many times the sand-blowing conditions may have recurred. Over a given area under these conditions sand would not only come, but it would go. What we see now is the final upshot of the process, the state of things that finally obtained when vegetation again got a hold and bound the sand together. Since that time the minor glaciations have come again and again; but the essence of glaciation is actual or potential moisture which would hold the sand together until vegetation had again resumed its sway.

The cardinal fact we have to deal with is that under the present pall of sand, or at any rate in its deeper layers, is a welldefined "Hoor" with numerous implements and flakes with patinations of a very special kind mingled with the undisturbed ashes of hearths; whilst on the surface or in the upper layers of the sand are large numbers of striated flints with their own special peculiarities of patination and surface change. It is clear that between the two sub-periods or groups of sub-periods the pall of sand was spread over the surface, indicating the last of the Desert periods that I have postulated as having preceded the onset of the Neolithic glaciating conditions. The increase in the power of sun-heat and light that led up to the Desert conditions is shown by the patination on one side only of the "floor"-pieces. 
Plate LIX.

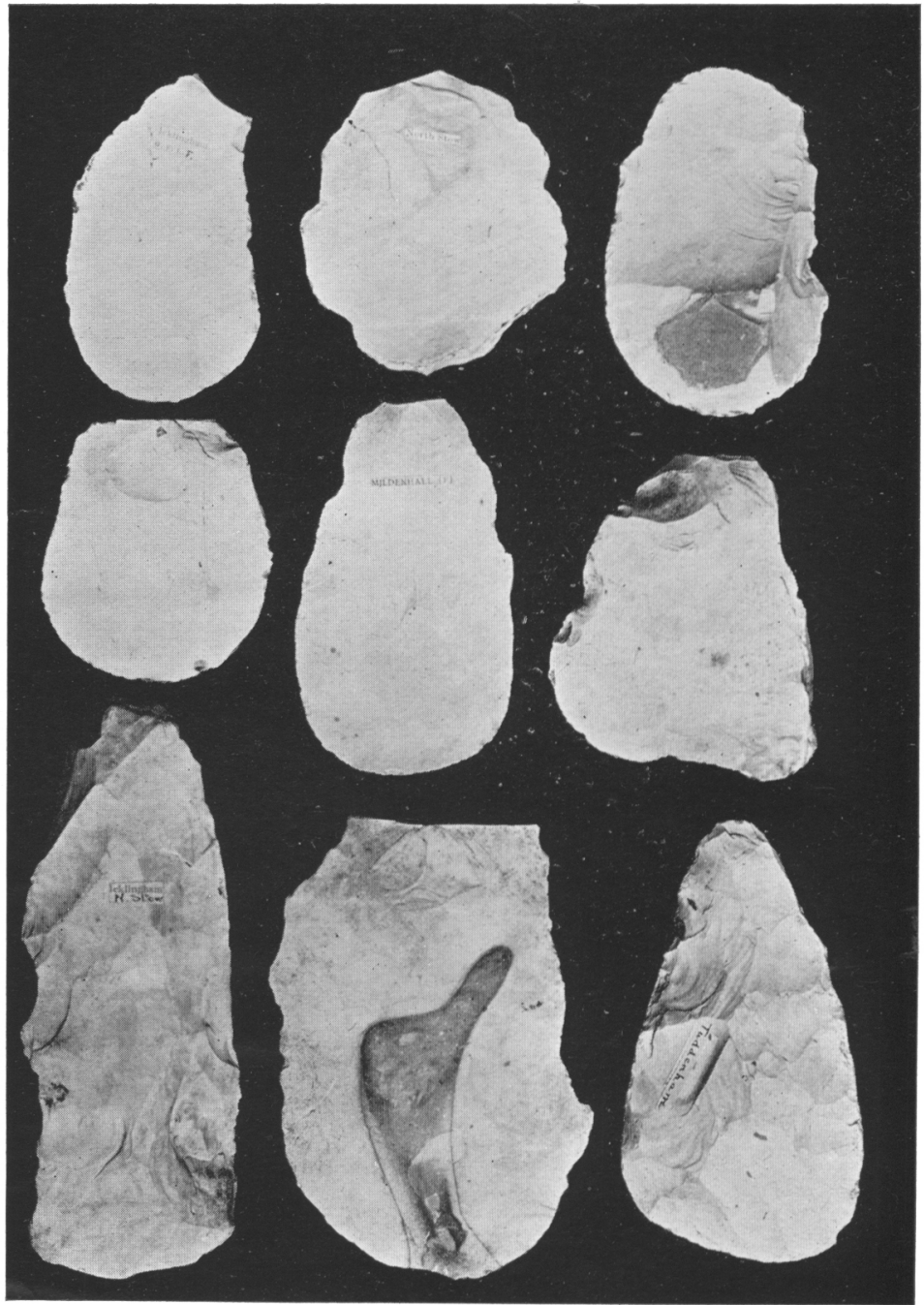

Implements from various districts, differently patinated on the two sides, the one side being dead white and the other blue. In this plate the white side is shown. Scale $\frac{1}{2}$ linear. 


\section{Plate LIX*.}

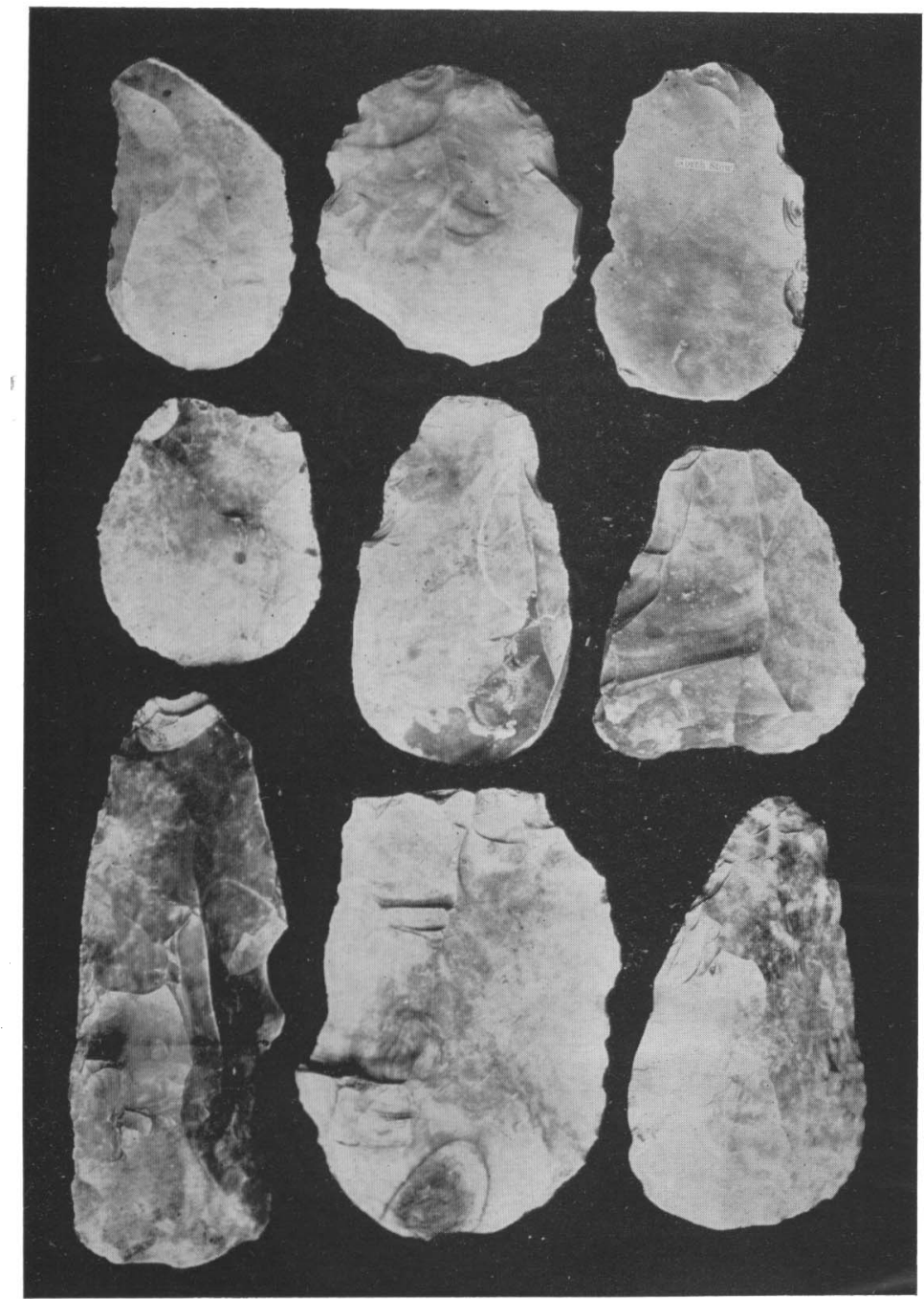

The same implements showing the blue side. In the originals the contrast of colour is much greater than is shown on the plates, blue being a difficult colour to bring out in the photograph. Scale $\frac{1}{2}$ linear. 
Plate LX.

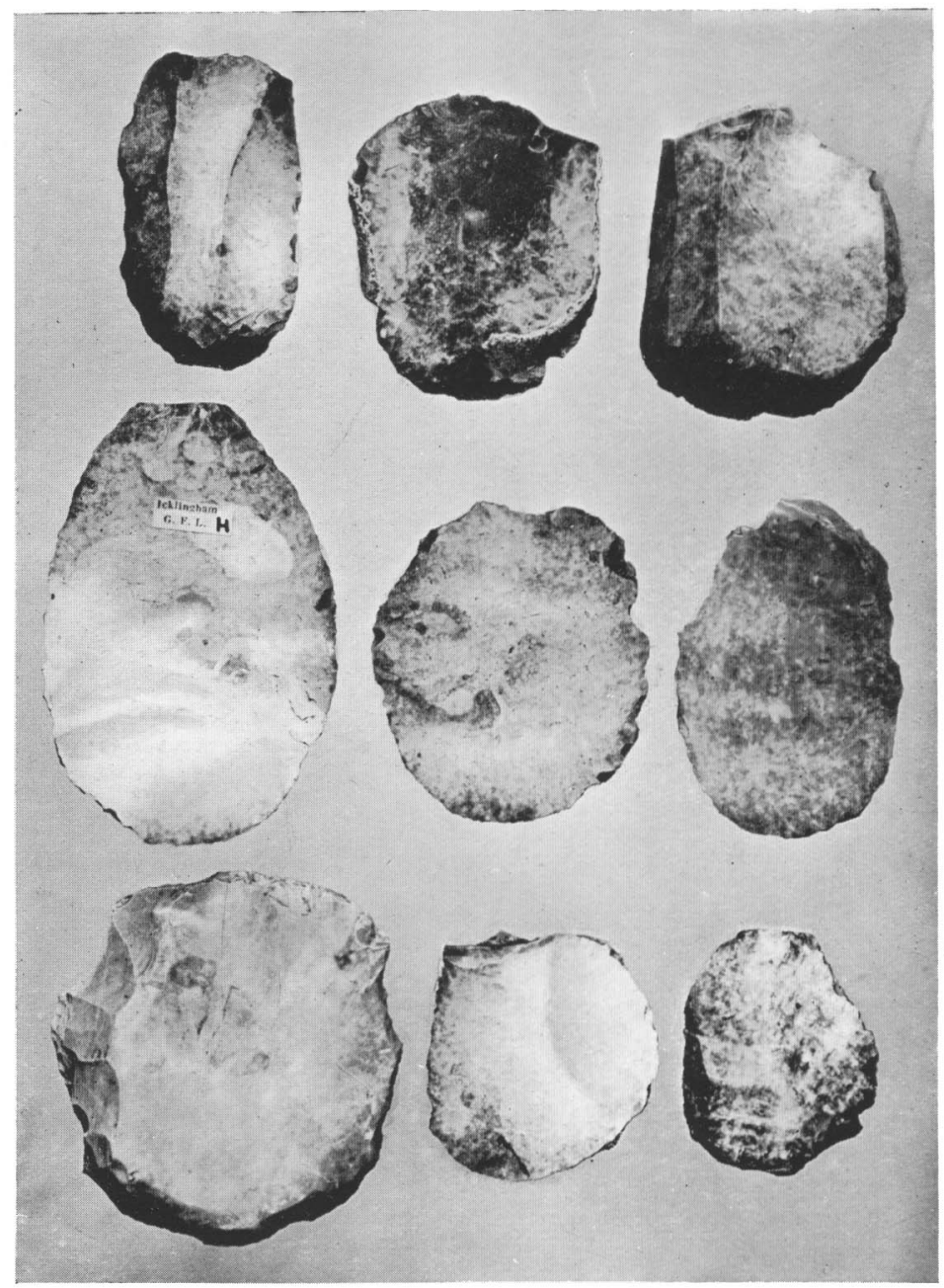

Scrapers, etc., with one-sided patination, from various districts in N.W. Suffolk and S.W. Norfolk. In this Plate the patinated side is shown. Scale $\frac{1}{2}$ linear. 
Plate $\mathrm{LX}^{*}$.

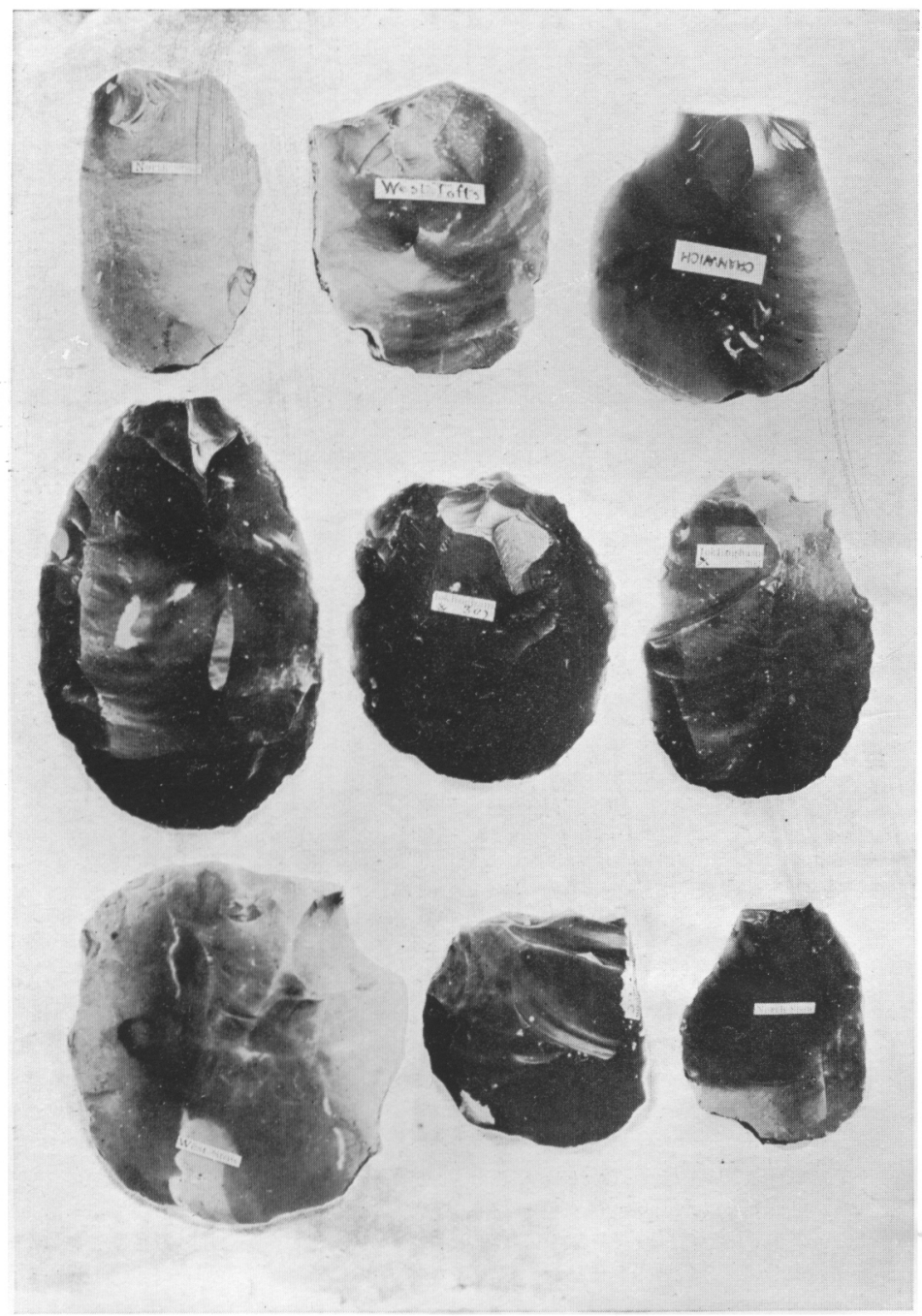

The same Scrapers as in Plate LX., showing the unpatinated side. The Scraper from West Stow, in the left-hand side of the bottom row, is partially polished. Scale linear 


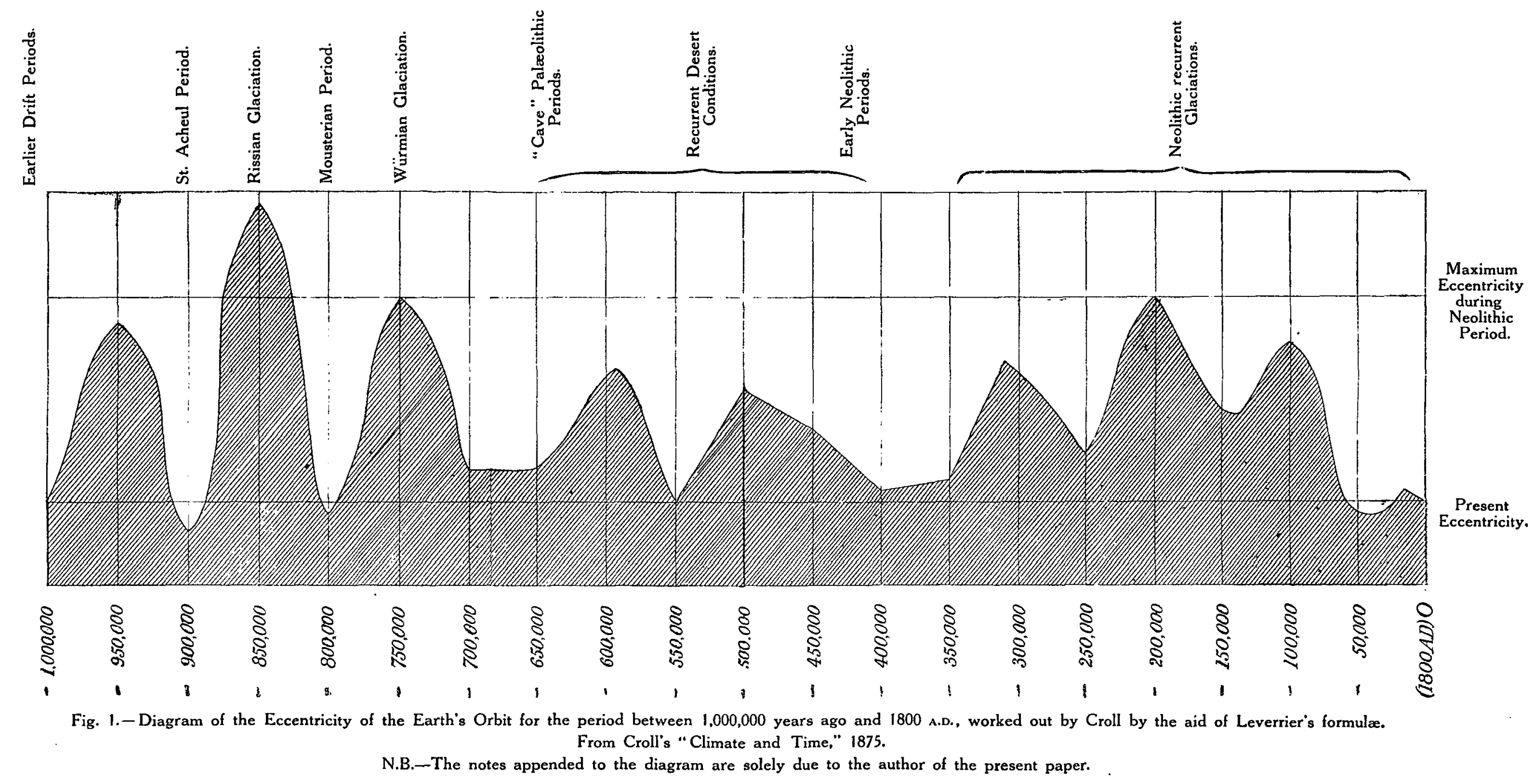


Plate LXI.

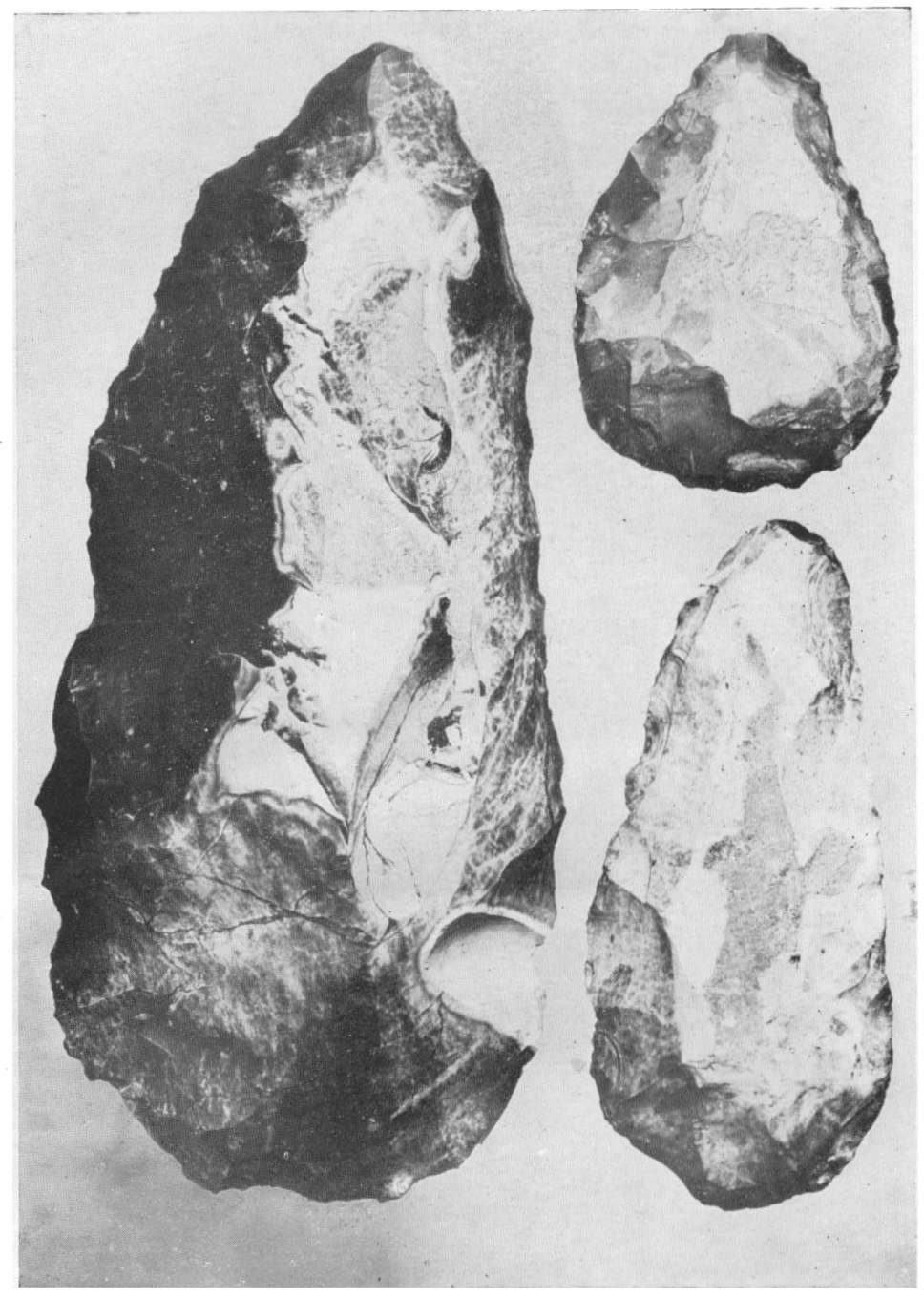

Implements from the "floor" discovered at Icklingham, showing one-sided patination. The patinated side. Scale $3 / 5$ th linear. 
Plate $\mathrm{LXI}^{*}$.

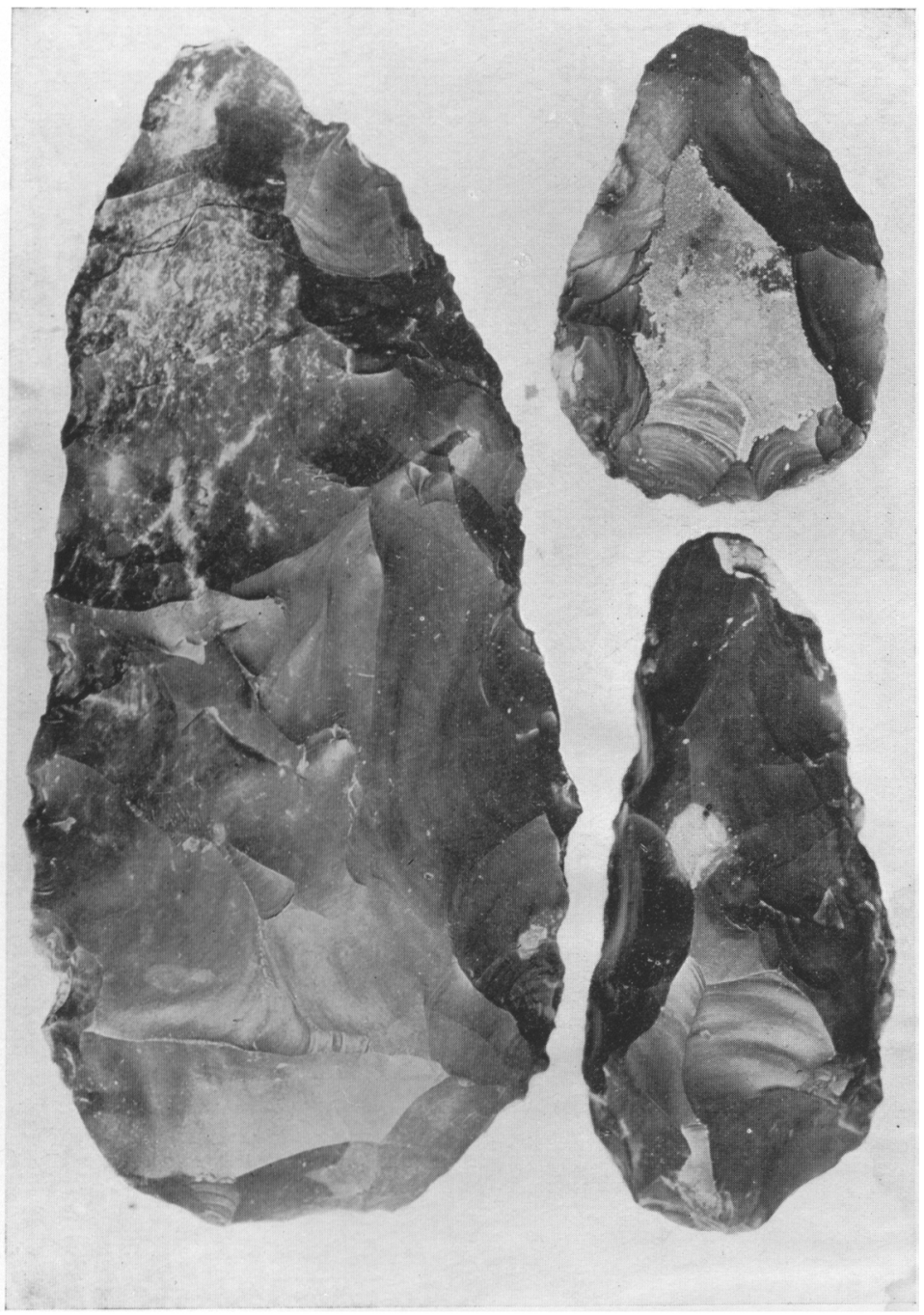

The same Implements showing the unpatinated side, 
Plate LXII.

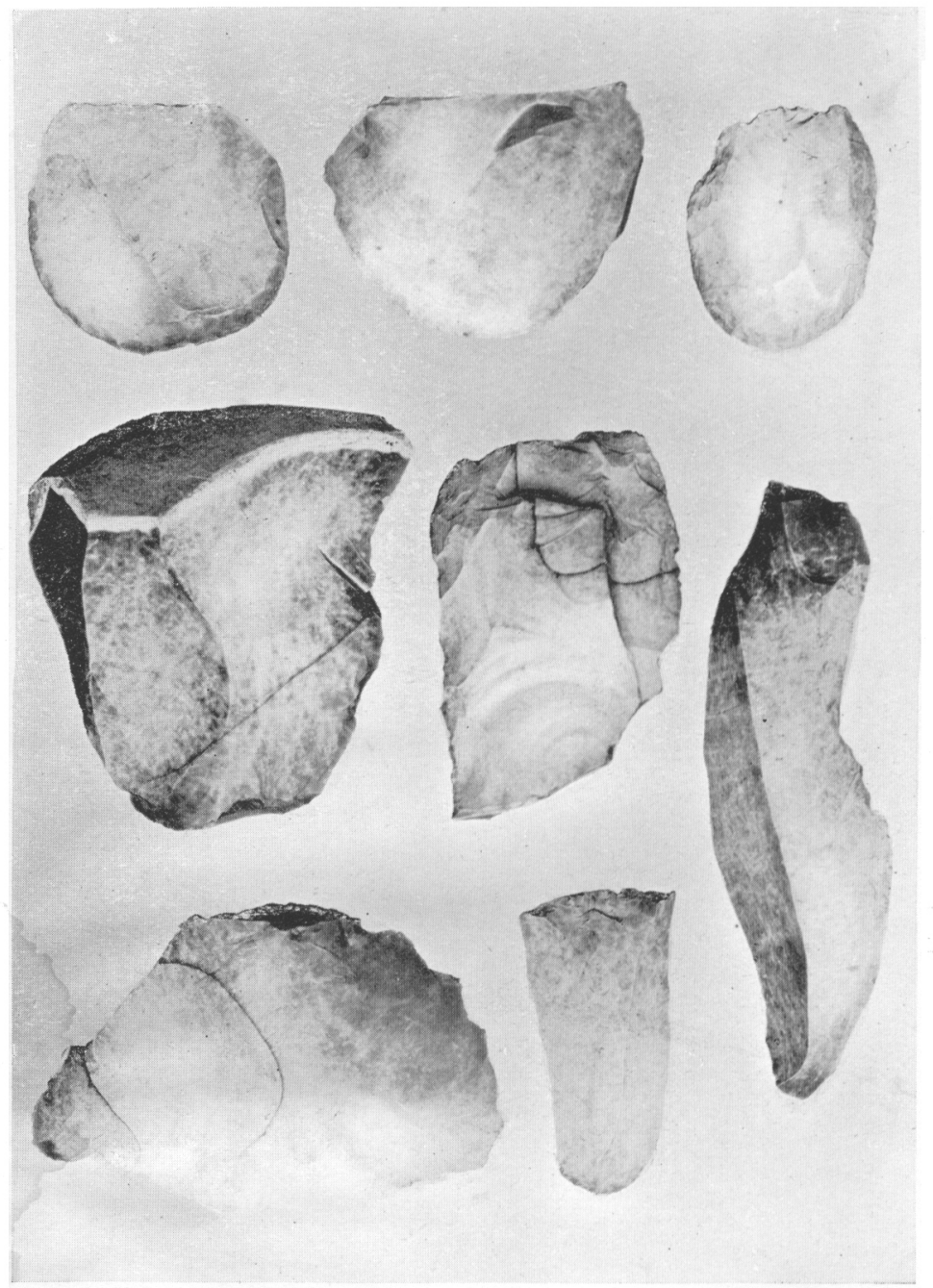

Scrapers and flakes from the "floor" discovered at Icklingham, having the same one-sided patination as seen in Plate LXII*. In this Plate the patinated side is shown. Scale $\frac{1}{2}$ linear. 
Plate LXII*.

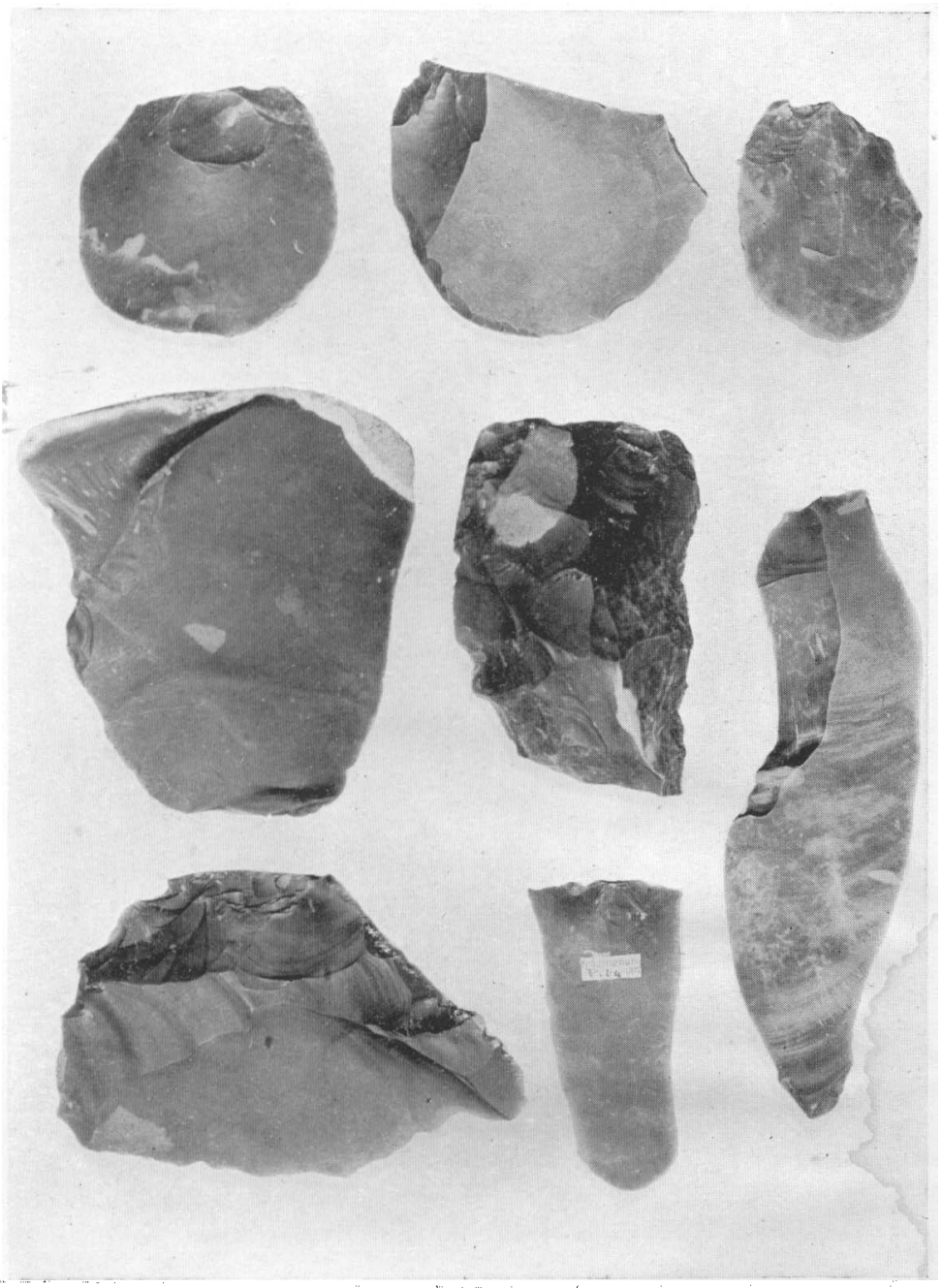

The same Scrapers and Flakes as in Plate LXIl., showing the unpatinated side. Scale $\frac{1}{2}$ linear. 
Plate LXIII.

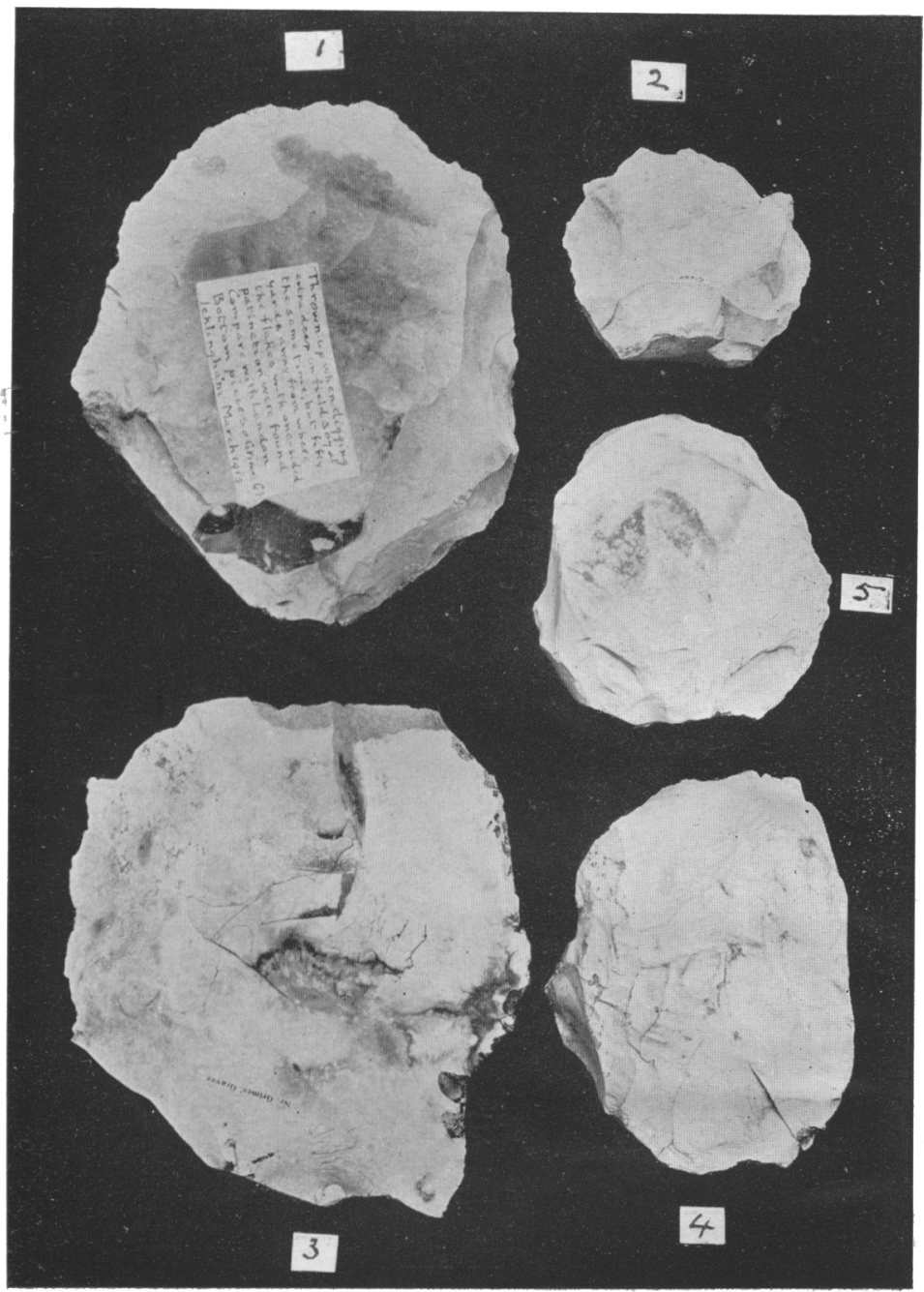

Showing white "lump" implements, Figs. 1 and 2, also from the "floor" at Icklingham, compared with similar "lump "implements from the neighbourhood of Grime's Graves (S.W. Norfolk), Fig. 3, and from the pits at Cissbury (Sussex), Figs. 4 and 5. Both sides are shown, to illustrate the difference between the relative patination of these pieces and of the series shown in the previous Plates. Scale $\frac{1}{2}$ linear. 
Plate LXIII*.

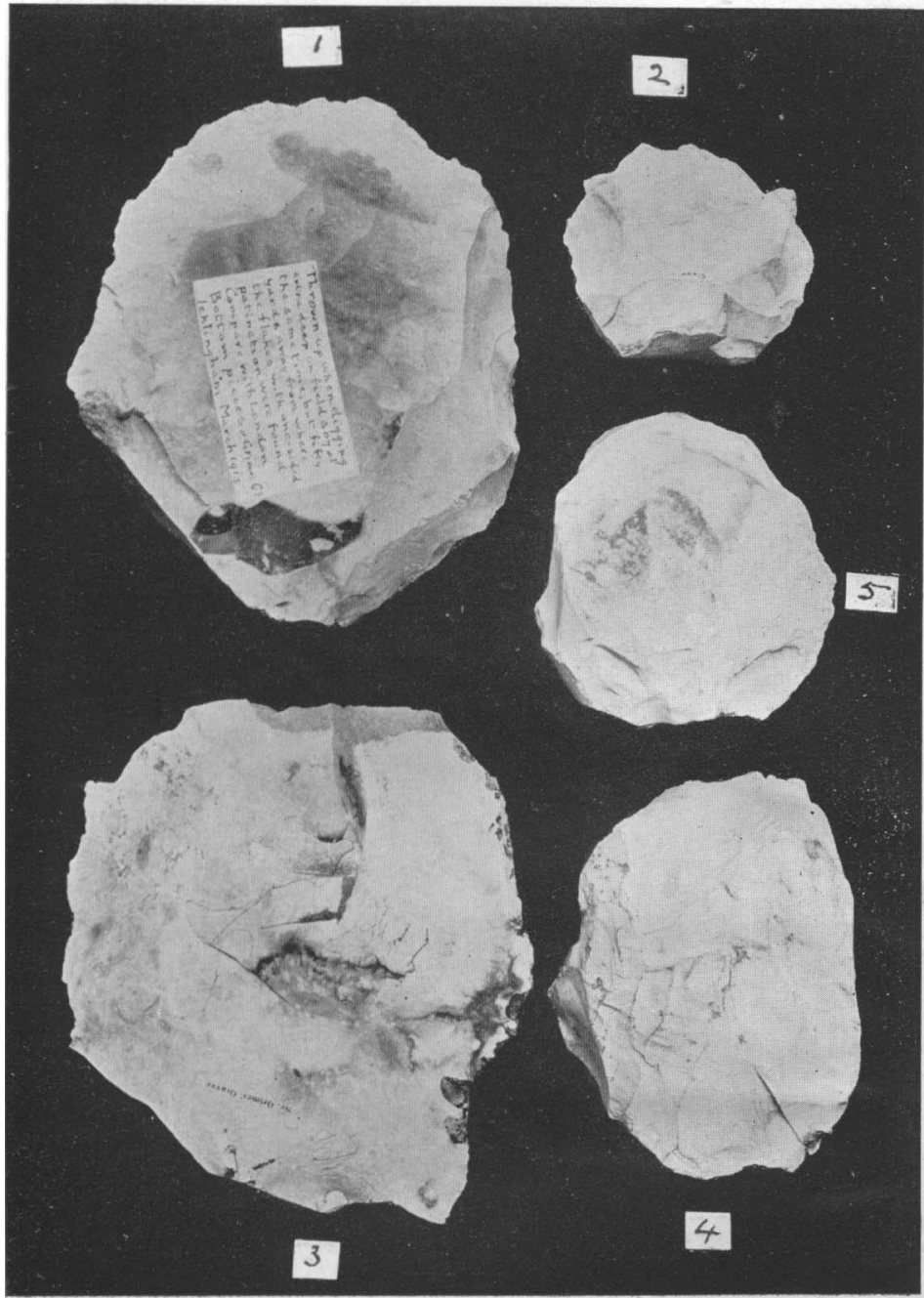

The reverse side of the pieces shown in Plate LXIII. 


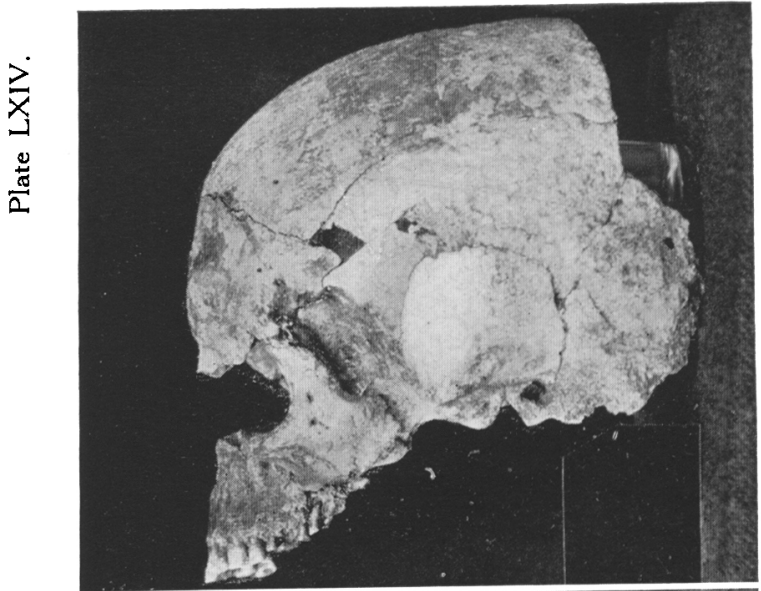

ผี่

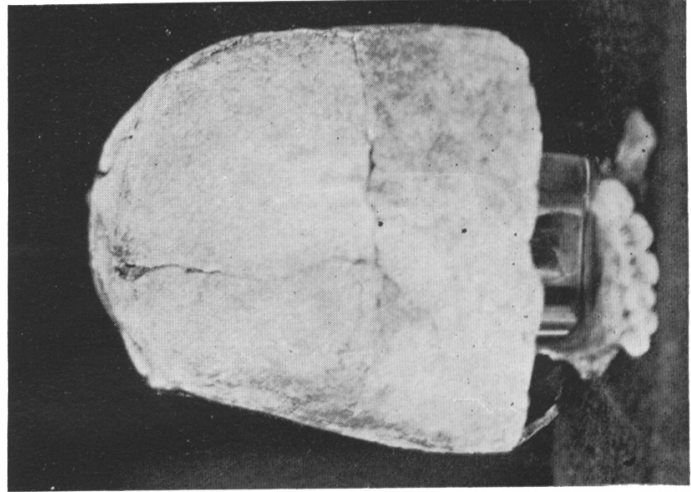

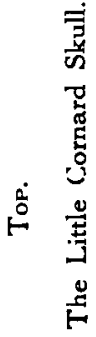

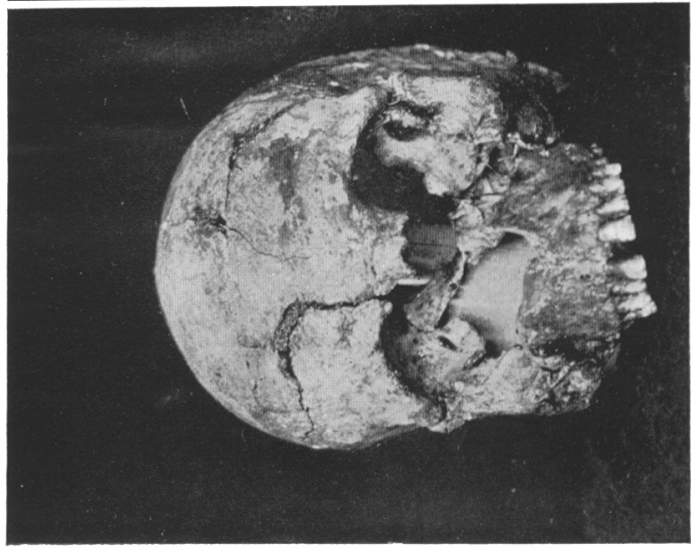

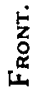

